\title{
Reducing the Mechanical Wear of Elbows and Pipes Due to Solid Particles Flow by Using Nano Coating Technique
}

\author{
Ali Sadiq Al-lthari ( $\sim$ alis.alathari@uokufa.edu.iq ) \\ University of Kufa, University of Kufa \\ Nabeel Al-Zurfi \\ University of Kufa, University of Kufa \\ Laith Zbbal Abd Ul Kareem \\ Ministry of Industry and Minerals /Company of Iraqi Cement / Najaf Cement Plant
}

\section{Research Article}

Keywords: Low Carbon Steel, Nano Tungsten Carbide (WC), Thermal spray, Wear Test, Numerical

Simulation

Posted Date: June 11th, 2021

DOl: https://doi.org/10.21203/rs.3.rs-568518/v1

License: (a) (1) This work is licensed under a Creative Commons Attribution 4.0 International License.

Read Full License

Version of Record: A version of this preprint was published at Scientific Reports on November 15th, 2021.

See the published version at https://doi.org/10.1038/s41598-021-01563-1. 


\title{
Reducing the Mechanical Wear of Elbows and Pipes Due to Solid Particles Flow by Using Nano Coating Technique
}

\author{
Ali Sadiq Al-Ithari ${ }^{1}$, Nabeel Al-Zurfi ${ }^{1}$, Laith Zbbal Abd UL Kareem ${ }^{2}$ \\ ${ }^{1-D e p a r t m e n t ~ o f ~ M e c h a n i c a l ~ E n g i n e e r i n g / ~ U n i v e r s i t y ~ o f ~ K u f a, U n i v e r s i t y ~ o f ~ K u f a ~, ~ P . O . B o x ~(21), ~ N a j a f ~}$ \\ Governorate, Iraq \\ Corresponding author: (Ali Sadiq Alithari , Email: alis.alathari@uokufa.edu.iq) \\ ${ }^{2-}$ Ministry of Industry and Minerals /Company of Iraqi Cement/Najaf Cement Plant, Najaf, Kufa, P.O.(25) \\ Najaf Governorate, Iraq. \\ These authors contributed equally to this work
}

\begin{abstract}
The failure problems of elbows and pipes facing a lot of industrial foundations like Cement Plants. This work investigated reasons and factors that cause the failure due to mechanical wear (Erosion) for the inside surface of elbows and pipes used in cement transportation (pneumatic conveyor) which manufactures from low carbon steel and finds out a method for reducing this failure. The technique of thermal spraying is using to coat the surface of samples with layers of nanoparticles of tungsten carbides (WC) of different thicknesses $(30,40$, and $50 \mu \mathrm{m})$. The test was done for these samples by placing them inside the elbow under the same operating conditions, moreover the standard test (pin on disc). The results showed a decrease in erosion rate by $71 \%$ for the sample coated with $50 \mu \mathrm{m}$ of WC layer, while the results of the pin on disc test showed a decrease in erosion rate by $97 \%$ for the thickness of $50 \mu \mathrm{m}$. The SEM Images showed a coating thickness layer of more than $50 \mu \mathrm{m}$ will be subjected to flacking and failure. The numerical simulation was also implemented to simulate the erosion profile inside the elbow, and the agreement with experimental results was $90 \%$.
\end{abstract}

Keywords: Low Carbon Steel; Nano Tungsten Carbide (WC); Thermal spray ;Wear Test, Numerical Simulation.

\section{INTRODUCTION}

The term slurry defines as "Non homogenous mixture of solid with liquid, gas or air". The flow of cement and high speed air mixture may cause mechanical wear for the internal surface of the pipes and elbows. The particle sizes of a solid vary from few microns to few millimeters. The effect of a high particle concentration influenced by different factors such as density amount, size, mass part, particles of solid and carrier density; and mortar can classified as an unstable factor depending on the size of the solid particle. The ability of solid particles to stabilize the carrier air is low[1]. Many fine powders, such as cement, which exhibit very low de-aeration rates, are suitable for dense-phase transport. Observation of the flow patterns, in horizontal pipes, when these powders are transported in dense phase reveals a stratified flow. A high concentration layer of fluidized material occupies the lower portion of the pipe. In the upper portion of the pipe, particles are suspended in the transport gas. The fluidized layer generated at the top and bottom of the pipes makes the particles suspended in the transport air [2]. Pipelines are important for transporting gases, liquids and solid materials for long distances from its main source to warehouses or silos. The cement industry is one of the important industries in the world, as it involved in a lot of application in building and construction [3]. The erosioncorrosion rate investigated $30^{\circ}, 60^{\circ}$, and $90 \mathrm{o}$ carbon steel elbows in multiphase flow containing sand particles. Qualitative techniques such as multilayer paint modeling and microscopic surface imaging were used to scrutinize the flow accelerated erosion-corrosion mechanism. The results shows the erosion rate for elbow of 90o higher than its in low angle elbows $\left(30^{\circ}\right.$ and $\left.60^{\circ}\right)$, also the high erosion rate occur in the upper half of elbow[4]. The transport of these conditions at high pressures up to 7 bar where the flow is turbulent and the particles of cement distributed directly across the cross-section of the pipe because of the high level of turbulence. Solid particles have a high impact on metal surfaces; causing damage to the surface and remove parts from it. This phenomenon called mechanical wear (Erosion). Erosion always occurs when the solid particles directly hit a solid surface. The mechanical erosion (wear) inside pipes plays a crucial role in the design and operation of the transporting system[5]. Investigations of wear are done for area of interest of different industries. Earlier efforts in the field of corrosion research began in 1960 in the industrial countries; this shows the complications of wear phenomenon [6].The mild steel used to study the wear occurred in pipes, where a mixture of compressed air and abrasive solid particles made. Their results indicated that the decrease in the bend curve leads to a decrease in the wear [7]. The erosion in mud transport tubes using ANSYS software studied numerically; the results showed that the erosion rate increases eight times[8]. The imperative used to simulate nanoindentation by powerful FEM software to extract plenty of mechanical properties like hardness, elastic modulus, endurance loads and 
various parameters like optimal thickness and optimal critical load, stress distribution and contact pressure between substrate and layer can be obtained through load-displacement curve A. [9]. The wear resistance and scratch investigated to St-37 mild steel after coating it with a nanoparticle of nickel-boron. The method used is electrical deposits and heat treatment with a period of ( 1 hour) at a temperature of $\left(400{ }^{\circ} \mathrm{C}\right)$; the results showed a decreasing in the wear rate about $50 \%$, while hardness increased about $28 \%[10]$. An experimental study on pipelines conducted to find out the reasons that lead to erosion by using a sand blasting device for different values of flow speed (20-80 m/s). The results showed that at a high speed and for a long time, the erosion was an abrasive mechanism, whereas at a low speed the erosion was due to plastic deformation[11]. A numerical study on mild steel conducted to find the wear. A steel pipe of $1.5 \mathrm{~m}$ in length and $50-250 \mathrm{~mm}$ diameter is used in their study. The sand mixed with water to form slurry and to control the speed from within the range of $2-8 \mathrm{~m} / \mathrm{s}$. The results showed that the greater the bending angle, the greater the wear. The largest wear ratio was at an angle of 30-60 degrees [12].The Nano coating layer of Tungsten Carbide is used to coat the surface of high chromium cast iron by using a thermal spray process and studied the improvement in the wear resistance and microhardness. The result showed that the microhardness increased by a ratio of 34\%[13]. It appears from the aforementioned literature review and to the best of the Authors' knowledge, the study of the mechanical wear caused by cement particles passing through a 90 degree pipe elbow with a unique method to reducing this mechanical wear by coating the internal surface of the elbow with layers of nanoparticles of tungsten carbides (WC) has not been studied extensively yet. The present experimental and numerical study would be a considerable contribution to the open literature and conducted the improving in wear resistance for coated inner surface of elbows and pipes that used in pneumatic conveyor for cement transportation.

\section{EXPERIMENTAL WORK}

\subsection{The Used Materials}

The metals of low carbon steel are used in the manufacturing of pipes and elbows in most of the cement plants. The chemical composition of low carbon steel listed in Table1. This material is also used in the preparation of samples tested inside elbow; pin on the disc, hardness test, and SEM image analysis.

Table1. Chemical composition of low carbon steel

\begin{tabular}{|c|c|c|c|c|c|c|c|c|c|c|c|}
\hline Composition & $\mathbf{C}$ & $\mathbf{S i}$ & Mn & $\mathbf{P}$ & $\mathbf{S}$ & $\mathrm{Cr}$ & Mo & $\mathbf{N i}$ & Al & $\mathbf{C u}$ & $\mathbf{F e}$ \\
\hline Experimental \% & 0.214 & 0.257 & 0.808 & 0.0101 & 0.0007 & 0.083 & 0.0034 & 0.0968 & 0.0418 & 0.176 & Bal. \\
\hline
\end{tabular}

\subsection{The Coating Material}

The Nano particles of tungsten carbide (WC) has Nano-size of $(55 \mathrm{~nm})$ used as a coating material to coat the low carbon steel samples. This nanoparticles has true density of $15500 \mathrm{~kg} / \mathrm{m}^{3}$, melting point of $2870{ }^{\circ} \mathrm{C}$, boiling point of $6000{ }^{\circ} \mathrm{C}$. Figure 1 shows the nanoparticles of tungsten carbides that used as coating materials.

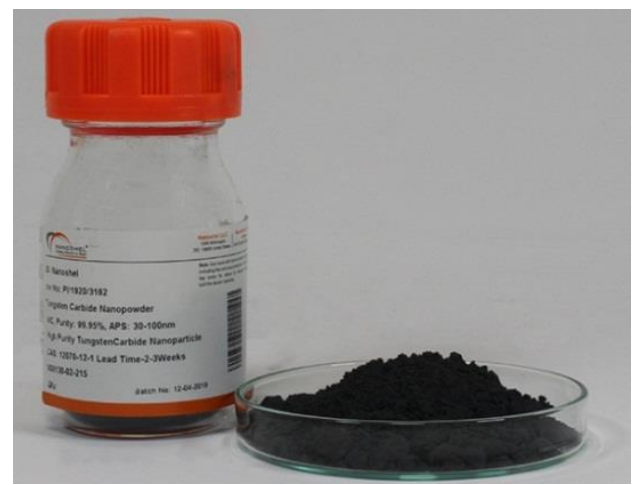

Fig.1. Nanoparticles of Tungsten Carbide (WC) .[13]

\subsection{Thermal Spray Technique}

High Velocity Oxi-Fuel (HVOF) used for metallic and non-metallic (ceramic) materials of the surface layer to form a coating layer for a semi-molten or molten state. Fuel oxygen and acetylene are both fed into the chamber by a gas flow rate ratio of 3:1 for oxygen and acetylene applied with a pressure of 10 bars for oxygen and 5 bars for 
acetylene. Both gases and nanoparticles controlled by special valves [14], shown in figure (2). The feeding rate of tungsten carbide nanoparticle was about $\left(1.3 * 10^{-2} \mathrm{gr} / \mathrm{s}\right)$.

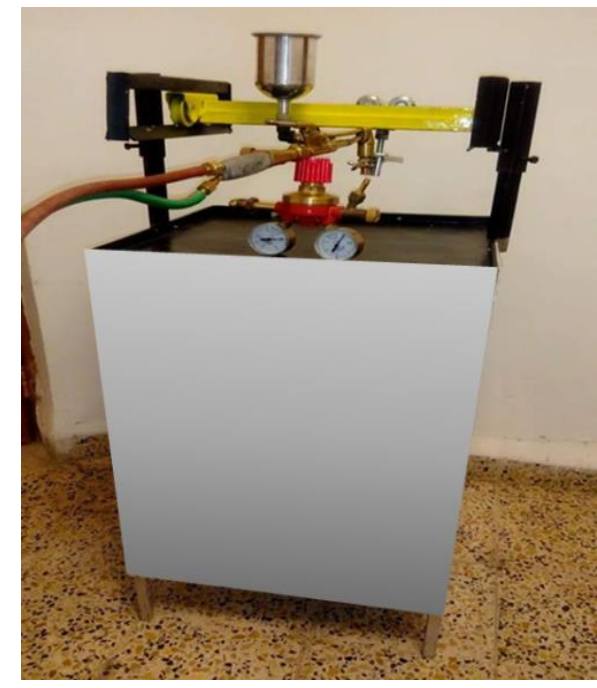

Fig.2. HVOF System.[15]

\subsection{Preparing the Samples inside the Elbow.}

The samples used to carry out the test inside the elbow prepared with dimensions of $70 * 30 * 5 \mathrm{~mm}$, and the location of samples inside elbow is set to ensuring that they exposed to real harsh operating conditions, and the flow is easy to run and pass through the forms to ensuring contact at every point on the surface of each sample. Furthermore, holes drilled into the sample to make it easier to install inside the elbow with the best types of fastening, shown in figure (3). A 10 degree cut angle created with the horizon at one side of each sample to avoid flow separation zones behind the site where the flow starts to pass over the sample. Additionally, the curvature of the surface of the samples was accurately made to make it easily fit inside the elbow.

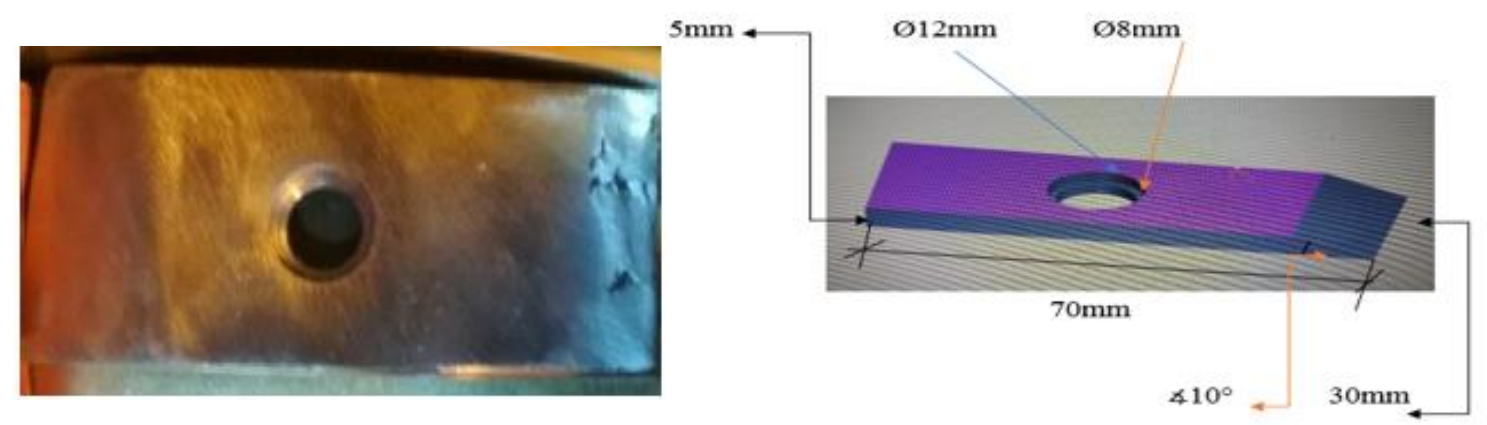

Fig.3. Samples inside Elbow

\subsection{Samples Testing inside the Elbow}

The steps of fixing the samples inside the elbow are as following:

1 - Four holes of $8.5 \mathrm{~mm}$ in diameter drilled in the elbow to fixing the samples.

2- Based on the pre-simulation results, a 10-degree cut angle was made with the x-axes at the front side of each sample (as shown in figure3) to prevent any expected flow separation zones behind the location where the flow starts to pass over the sample and keep the flow fully attached to the sample's surface

3- Measuring the weight of each sample before fixing them on the inner surface of the elbow.

4- The number of samples was four from low carbon steel and fixed on the inner surface of the elbow.

5- The samples preparation were as following: one sample without coating, one sample with a coating thickness of $30 \mu \mathrm{m}$, one sample with a coating thickness of $40 \mu \mathrm{m}$, and one sample with a coating thickness of $50 \mu \mathrm{m}$.

The site chosen in the inner surface of the elbow, which is expected to subject to the most severe conditions by cement particles and flow velocity; and the samples placed on the inner circumference of the elbow using steel bolts, shown in figure (4). 

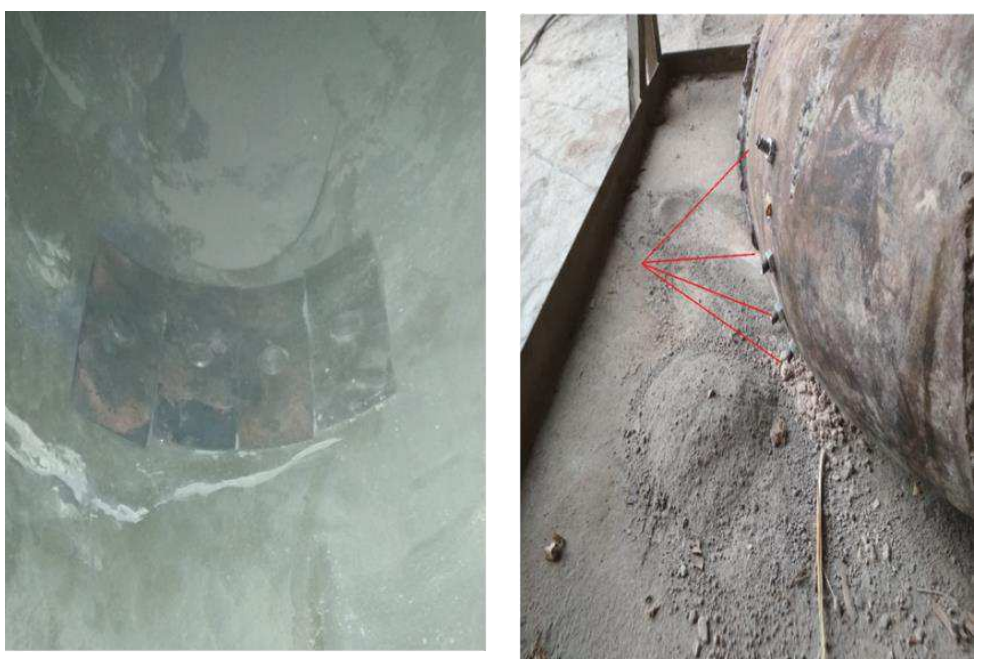

Fig.4. Samples Installation inside the Elbow

\subsection{Preparation of Wear test (Pin on Disc) Samples}

The samples preparing for wear test (pin on disc) from low carbon steel of diameter (40 mm) and thickness of (10 mm) according to the standard specification of (ASTM G-99-17) [16]. The surface of samples smoothed in the laboratories of the faculty of Engineering at the University of Kufa/ IRAQ. The pin rotation diameter chosen according to the rotating speed (400, 500 r.p.m.) and the applied load on the pin is $20 \mathrm{~N}$ according to standard specification, the abrasive wear occurs by mechanism of (deformation and cutting) for the tested samples surface and abrasive particles will removed continuously due to the high rotation speed as shown in figures (5) and (6).

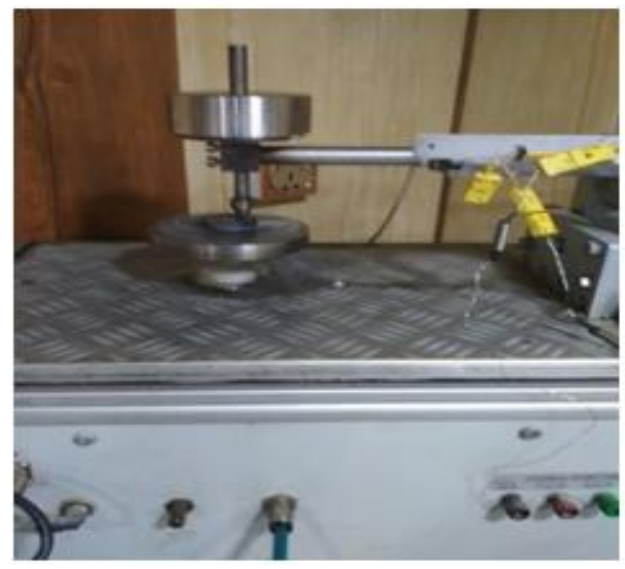

Fig.5. Pin on Disc Tester

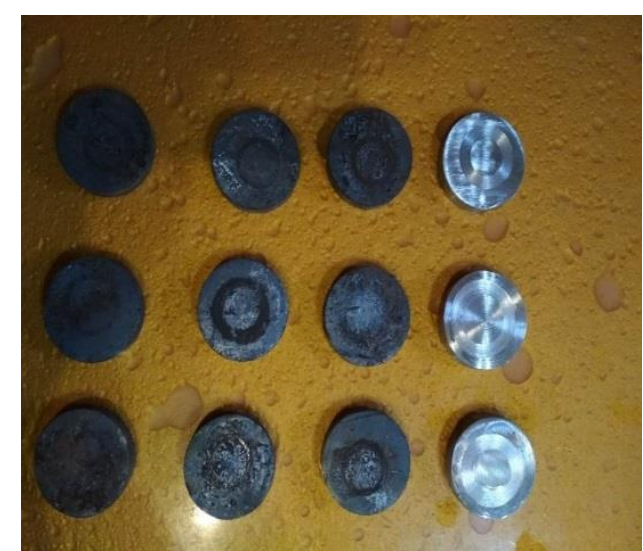

Fig.6. Wear samples Test after Testing (Coated and uncoated)

\section{MATHMATICAL AND NUMERICAL FORMULATION}

\subsection{Governing Equations and particles tracking method}

The first step in the predicting of erosion is the flow field simulation. Fluid flow modeled by time-averaged Navier-Stokes equations to calculate the flow fields presented. RANS method used to model the turbulent flow. Airflow assumed incompressible, Newtonian fluid with constant fluid properties, three-dimensional, unsteady, and in turbulence mode. Hence, the continuity, momentum, and turbulence equations for an incompressible fluid, three-dimensional, and time-dependent are [17]:

\section{- Continuity equation:}

$$
\frac{\partial \rho}{\partial t}+\nabla \cdot(\rho \vec{U})=0
$$


- Momentum equations:

$$
\frac{\partial}{\partial t}(\rho \vec{U})+\nabla \cdot(\rho \vec{U} \otimes \vec{U})=-\nabla \cdot P+\nabla \cdot\left[\left(\mu+\mu_{t}\right)\left(\nabla \cdot \vec{U}+(\nabla \cdot \vec{U})^{T}\right)\right]-\frac{2}{3} \nabla \cdot \rho k \delta_{i j}
$$

Where: $\mathrm{U}$ is the time-averaged speed and $\boldsymbol{p}$ is the pressure.

In order to find the turbulent eddy viscosity $\left(\boldsymbol{\mu}_{\boldsymbol{t}}\right)$, the Menter k- $\boldsymbol{\omega}$ SST turbulent model adopted in the current study as follows [18] :

$$
\begin{aligned}
& \frac{\partial}{\partial t}(\rho k)+\nabla \cdot(\rho k \vec{U})=\nabla \cdot\left[\left(\mu+\frac{\mu_{t}}{\sigma_{k}}\right) \nabla \cdot k\right]+P_{k}-\beta_{1} \rho k \omega \\
& \quad \frac{\partial}{\partial t}(\rho \omega)+\nabla \cdot(\rho \omega \vec{U})=\nabla \cdot\left[\left(\mu+\frac{\mu_{t}}{\sigma_{\omega 1}}\right) \nabla \cdot \omega\right]+\gamma\left(2 \rho \delta_{i j} \cdot \delta_{i j}-\frac{2}{3} \rho \omega \nabla \cdot \vec{U} \delta_{i j}\right) \\
& -\beta_{2} \rho \omega^{2}+2 \frac{\rho}{\sigma_{\omega 2} \omega} \nabla \cdot(k \cdot \omega)
\end{aligned}
$$

Where:

$$
\boldsymbol{P}_{k}=2 \mu_{t} \delta_{i j} \cdot \delta_{i j}-\frac{2}{3} \rho k \nabla \cdot \vec{U} \delta_{i j} \text { and } \delta_{i j}=\frac{1}{2}\left(\frac{\partial u_{i}}{\partial x_{j}}+\frac{\partial u_{j}}{\partial x_{i}}\right)
$$

Thus, the turbulent eddy viscosity can calculated from $\boldsymbol{\mu}_{\boldsymbol{t}}=\boldsymbol{\rho} \boldsymbol{k} / \boldsymbol{\omega}$

The empirical constants and $\operatorname{Pr}_{t}$ presented in the above equations can set to the following values [18]:

$\sigma_{k}=1.0, \sigma_{\omega 1}=2.0, \sigma_{\omega 2}=1.17, \gamma=0.44, \beta_{1}=0.09, \beta_{2}=0.083, P r_{t}=0.9$

Once the simulation of the flow field has been completed, the particle tracking technique applied. In this technique, STAR CCM ${ }^{+}$CFD models motion of particles as a discrete phase (solid particle) in a Lagrangian reference frame and calculates the trajectories of these particles using Newton's second law of motion (equation of particle motion) on an individual scale. The particle momentum can formulate as[18];

$$
\boldsymbol{m}_{\boldsymbol{p}} \frac{d u_{p}}{d t}=F_{D}+F_{G}+F
$$

Where: $\boldsymbol{m}_{\boldsymbol{p}}, \boldsymbol{u}_{\boldsymbol{p}}$ and $\mathrm{t}$ are mass of particle in $\mathrm{kg}$, particle speed in $\mathrm{m} / \mathrm{s}$, and time in second, respectively. $\boldsymbol{F}_{\boldsymbol{D}}$ Represents the drag force acting on the particle in $\mathrm{N}$, and $\boldsymbol{F}_{\boldsymbol{G}}$ represents the gravitational force in N. Any other external forces are included in F.

The drag force can compute as;

$$
\boldsymbol{F}_{D}=\left(\frac{1}{\tau_{p}}\right) \boldsymbol{m}_{p}\left(u-u_{p}\right)
$$

Where $\boldsymbol{\tau}_{\boldsymbol{p}}$ the response time of particle speed, $\mathrm{u}$ is the instantaneous flow velocity which can calculated from $\boldsymbol{u}=\boldsymbol{U}+$ $\boldsymbol{u}$ where $U$ is the time-averaged velocity calculated directly from equation 4 and $\boldsymbol{u}$ is the turbulent fluctuation speed, which defined as;

$$
\dot{u}=\sqrt{\frac{2 k}{3}}
$$

Where: $\mathrm{k}$ is the turbulent kinetic energy.

The gravitational force formulated as;

$$
F_{g}=m_{p} g \frac{\left(\rho_{p}-\rho\right)}{\rho_{p}}
$$

Where: $\rho_{p}$ is density of the particle, $\rho$ is the density of the fluid, and $\mathrm{g}$ is the gravitational direction.

\subsection{Erosion model}

Erosion modeling predicts the rate of erosion from particle impact on solid boundaries. In calculating the erosion rate, STAR-CCM+ accumulates the damage that each particle impacts cause. This calculation is done by selecting a correlation for the erosion ratio, that is, the mass eroded from the wall per unit mass of impinging particles. Erosion rate is computed by accumulating the damage on contact boundary faces that each solid particle impact does on the face [19]:

$$
E_{f}=\frac{1}{A_{f}} \sum_{\pi(f)} \dot{m}_{\pi} e_{r}
$$


Where $A_{f}$ is the area of each face, $\dot{m}_{\pi}$ is the particles mass flow rate in parcel $\pi$, and $e_{r}$ is the erosion ratio. Different correlations are available in the open literature to model the erosion rate. In the present study, the erosion ratio $e_{r}$ has been computed using the following Oka correlation.

\subsubsection{Oka Correlation}

The Oka correlation [19 \& 20] for the erosion ratio is:[19]

Where:

$$
e_{r}=e_{90} g(\alpha)\left(\frac{v_{\text {rel }}}{v_{\text {ref }}}\right)^{k_{2}}\left(\frac{D_{p}}{D_{\text {ref }}}\right)^{k_{3}}
$$

- The angle function $g(\alpha)$ is defined as:

$$
g(\alpha)=(\sin \alpha)^{\mathrm{n}_{1}}\left(1+\mathrm{H}_{\mathrm{v}}(1-\sin \alpha)\right)^{\mathrm{n}_{2}}
$$

- $\mathrm{n}_{1}, \mathrm{n}_{2}$ are constants.

- $\mathrm{H}_{\mathrm{v}}$ is the Vickers hardness of the removed material in units of GPa.

- $\mathrm{v}_{\text {rel }}$ is the relative velocity of the solid particle with respect to the contact boundaries, $\left|\mathrm{v}_{\text {rel }}\right|,\left(\mathrm{v}_{\text {rel }}=\mathrm{v}_{\text {particle }}-\mathrm{v}_{\text {wall }}\right)$.

- $\mathrm{v}_{\mathrm{ref}}$ is the reference velocity.

- $\mathrm{D}_{\text {ref }}$ is the reference diameter.

- $\mathrm{k}_{2}$ and $\mathrm{k}_{3}$ are constants.

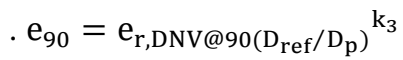

\subsection{Boundary Conditions}

Figure 7 shows the simulated geometry, which the standard elbows that has already been in use as one of the cement transport equipment at Al-Najaf cement factory. The elbow has a diameter of $\mathrm{D}=19 \mathrm{~cm}$ with a curvature ratio (R/D) equal to 2.78. A constant pressure boundary condition applied at the outlet section with a pressure equal to atmospheric pressure (101325Pa). The initial flow and boundary conditions have been listed in Table 2.

Table2. Initial boundary conditions of flow inside elbow and pipes. [20]

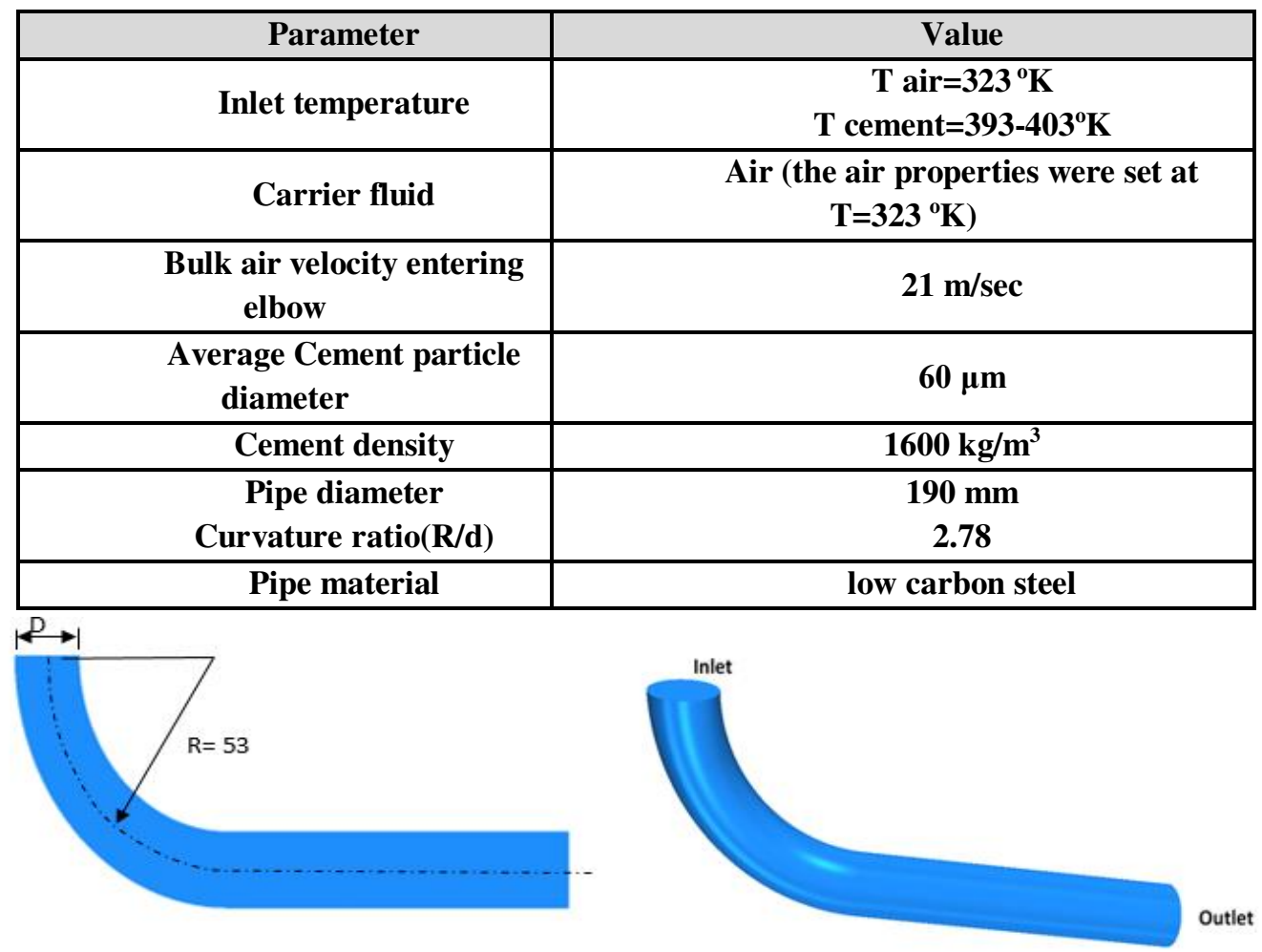

(a) Schematic of standard elbow geometry

(b) 3- D elbow geometry.

\subsection{Grid Generation}

Fig.7. Schematic of the elbow.

A three-dimension, multi-blocks, hexahedral and polyhedral meshes created using the mesh generation section of STAR $\mathrm{CCM}^{+}$code to generate the entire computational domain of the elbow. The mesh generation structure shown in figure $8(\mathrm{a}$, and $\mathrm{b})$. Grid independence study performed using a four-mesh study to ensuring that the simulations 
acquired using the selected grid is independent of the grid size. Overall erosion rate used as an indicator of convergence, and the results of the grid independence test illustrated in Table (3). Consequently, the current simulations performed using the mesh number of $(4,157,524)$ based on the overall erosion rate results obtained from the grid independence study.

Table3. Mesh refinement study

\begin{tabular}{|c|c|}
\hline Number of grids & Overall Erosion Rate (g/hr) \\
\hline $1,013,219$ & 0.3924 \\
\hline $2,452,810$ & 0.4081 \\
\hline $4,157,524$ & 0.4106 \\
\hline $5,609,287$ & 0.4166 \\
\hline
\end{tabular}

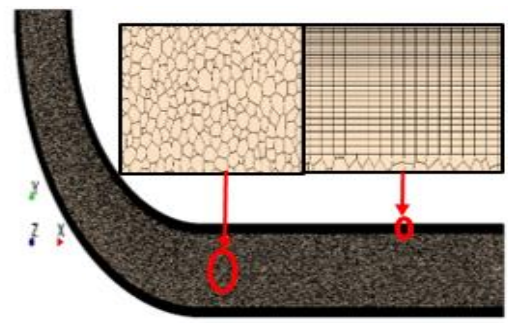

(a) Elbow section mesh

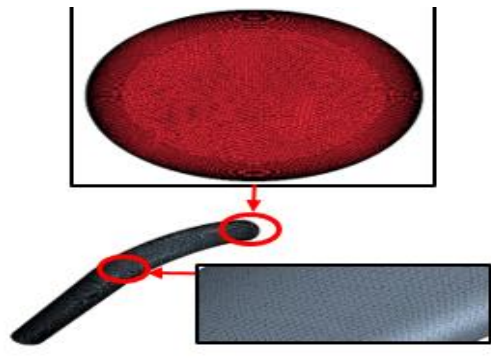

(b) Surface mesh on and around the extrados and inlet of the elbow

Fig.8. Mesh of elbows model.

\subsection{Numerical procedure:}

The Eulerian-Lagrange simulation performed within the STAR CCM+ firstly solves the system governing equations discretized by the finite volume technique along with using of the SIMPLE algorithm method. In conjunction with this, the Menter $\mathrm{k}-\omega$ SST RANS turbulence model employed to predict the turbulence effects on the air flow field [17]. The relaxation Gauss-Seidel scheme applied to solve iteratively the generated set of linear algebraic equations to calculate the values of velocity, pressure, etc. A time step of $\sim 1 \times 10^{-4} \mathrm{sec}$. was used for all calculations. Airflow field simulation was run for 24 time cycle to reach stable statistics results of the flow field and turbulence quantities. The solution procedure continued until reach the error criterion of $10^{-5}$ for every component to satisfy the solution convergence criterion.

\section{RESULT and DISSCUSSION}

\subsection{Results of Experimental Work}

\subsubsection{Sample tested inside Elbow}

The tested samples were 4 samples, one without coating and three with different coating thickness 30,40, and $50 \mu \mathrm{m}$ which are gotten from different periods of coating time 10,20,30 sec, while the time coating more than $30 \mathrm{sec}$ (more than $50 \mu \mathrm{m}$ ) will give unstable coating layers(cracking, flacking ,and failure) due to the lack of adhesion between the sample surface and coating layer as shown in figure (9), and that occur due to feeding rate of nanoparticles ,the flame control, and person ability to controlling the coating process. The operating conditions for cement transporting pipes and elbows was 30 tons/hr, and the total time was 170 working hours during which about 5100 tons were passing through the pipe. The graph shown in figure (10) shows the relationship between the coating thickness and weight loss ratios, where it can show that when increasing the coating thickness to $50 \mu \mathrm{m}$, the lowest percentage of weight loss reached to $3.62 \%$, which indicates on homogeneity, reduction of defects, the high strength and hardness of coating layer, and regular spread and high intensity of (WC) that make elbow and pipe surface more resistant to abrasion and ablation. The improvement ratio in wear resistance for coated sample reaches to $71 \%$ for maximum coating thickness of $50 \mu \mathrm{m}$, as shown in figure (11). 


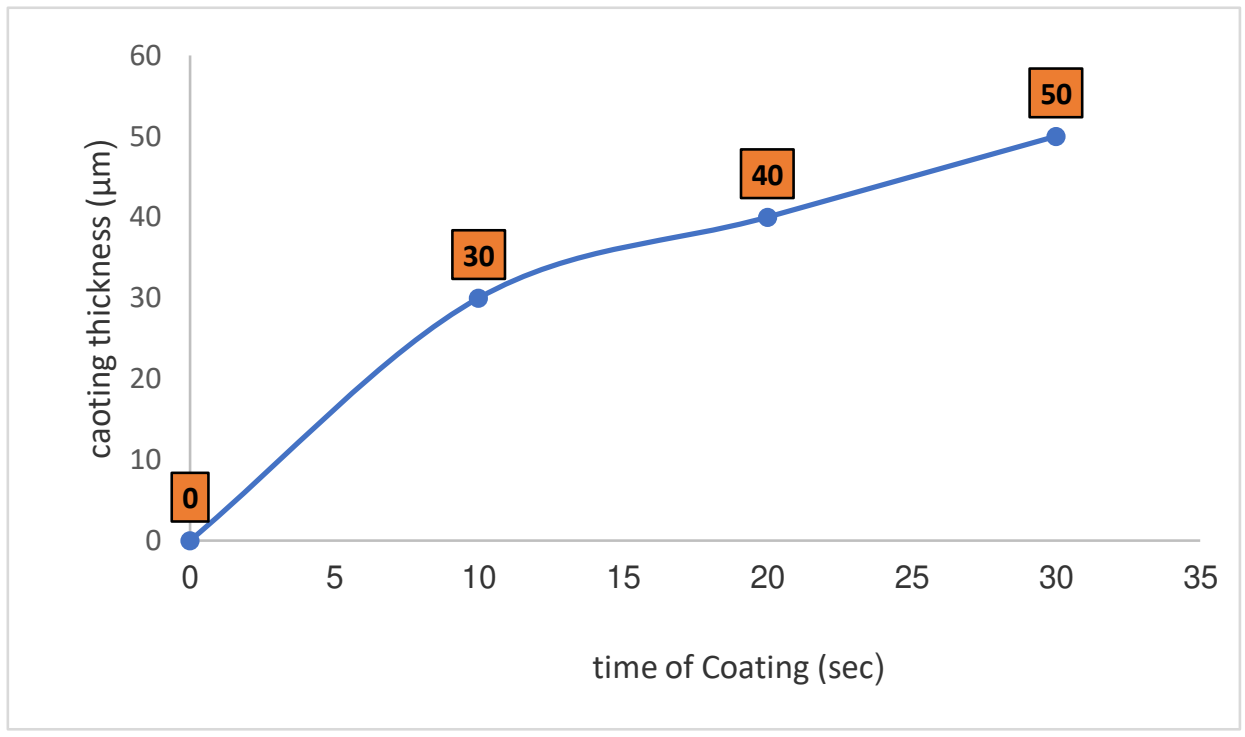

Fig.9. Coating layer thickness in $(\mu \mathrm{m})$ with time of coating(sec).

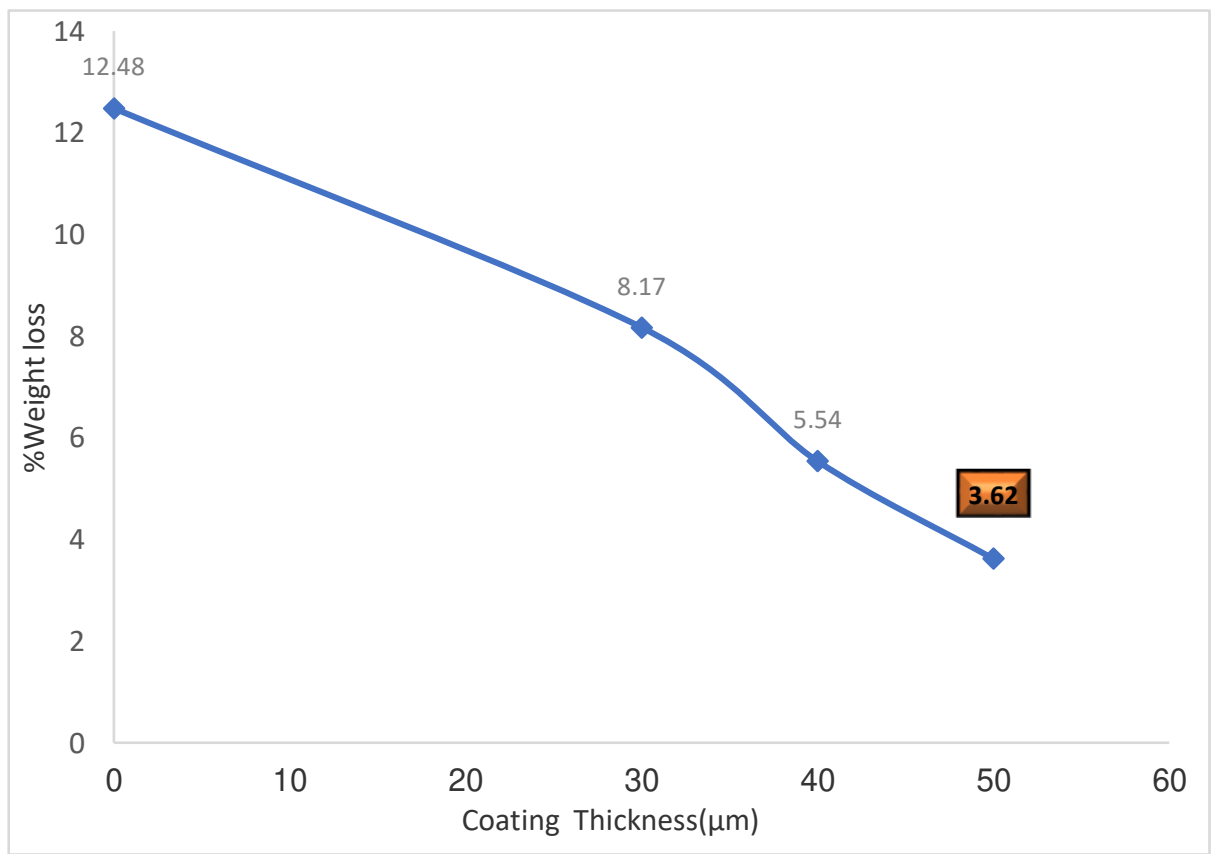

Fig.10. The weight Loss ratio with Coat Thickness of Samples inside Elbow 


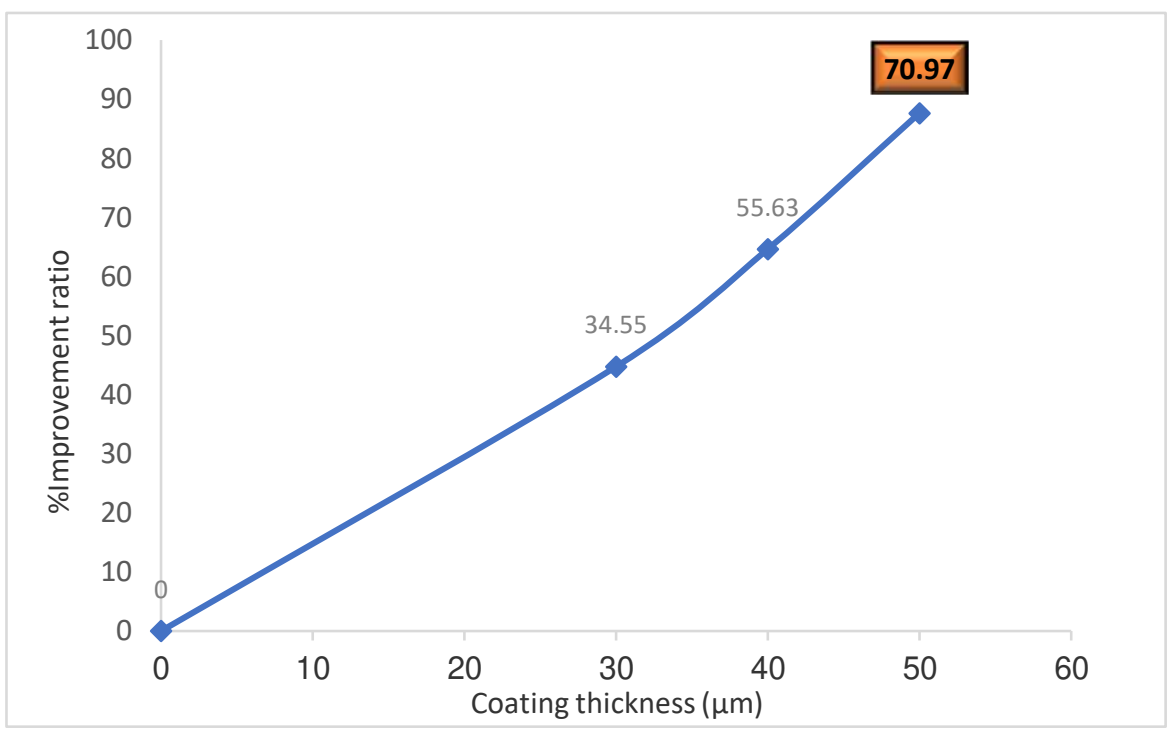

Fig.11. Improvement ratio of Wear resistance for samples inside the elbow

\subsubsection{Wear Test (Pin on Disk) Results}

Wear test based on weight loss, which was conducted on samples in the laboratory to compare between the wear resistance of coated and uncoated samples and simulate the result from the experimental test and its conformity. This test done with (24) samples, through which a comparison made between samples without coating, (6) samples coated with a thickness of $30 \mu \mathrm{m},(6)$ samples coated with a thickness of $40 \mu \mathrm{m}$, and finally (6) samples with a $50 \mu \mathrm{m}$ coating, the samples were weighed before the test by an exact digital balance (4 digit), used a load of ( $20 \mathrm{~N})$ for each sample, and used angular velocity of (400, 500 r.p.m.), according to the standard specifications of (American Society for Testing and Materials,2017). The time to complete the test for each sample was (10 minutes). The figure (12) the results shows the wear resistance of samples without coating layer under conditions of (20N) loading and angular velocity $(400,500$ r.p.m.) that the weight loss increase with increase rotating speed and friction and the best the weight loss rate at speed (500 r.p.m.) was $(0.3905 \%)$.

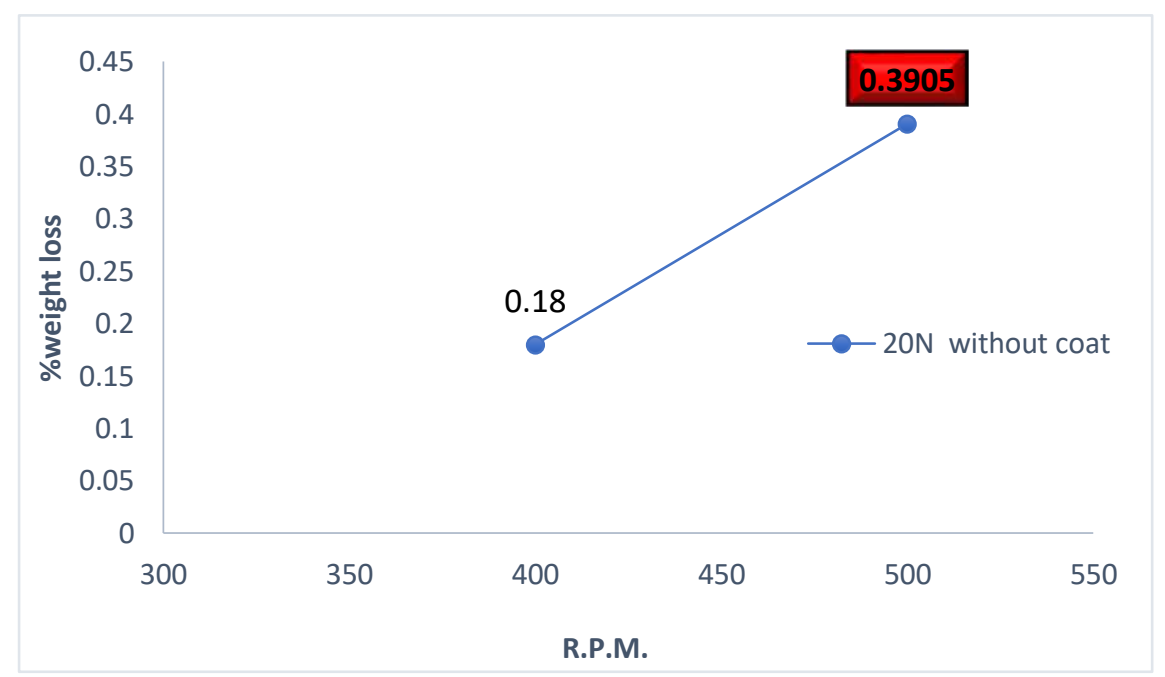

Fig.12.Weight loss with angular velocity for uncoated samples .

The figure (13) shows the results of wear test(pin on disc) for samples with a coating layer thickness 30,40 , and $50 \mu \mathrm{m}$ under conditions of $(20 \mathrm{~N})$ loading and angular velocity 400,500 r.p.m., the weight loss increase with increase rotating speed and friction, the lowest weight loss rate was at speed 500 r.p.m., for sample coated with $50 \mu \mathrm{m}$ with value \% 0.0117 , while figure (14) shows the improvement ratio for wear resistance reach to $97 \%$ for sample coated with $50 \mu \mathrm{m}$ thickness due to the high strength and homogeneity of the coating layer, that makes it more resistant for erosion by cement particles. 


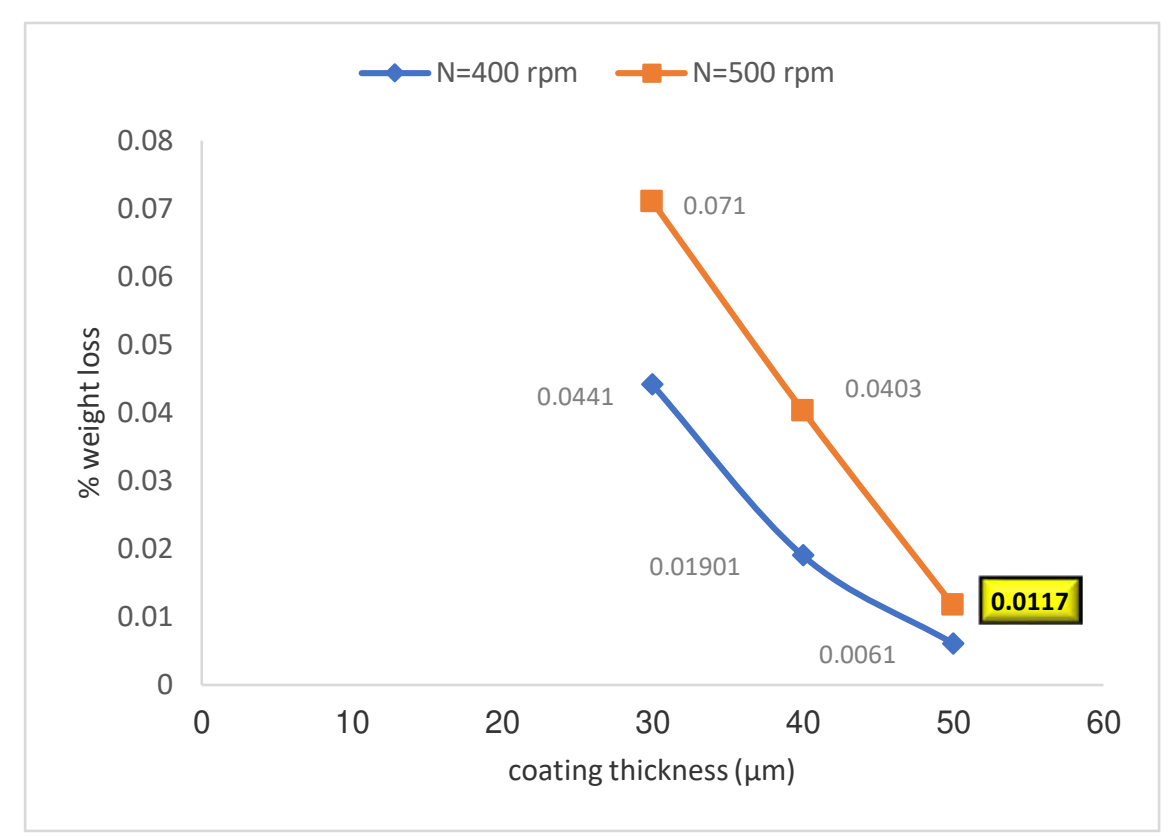

Fig.13. Coating layer thickness and weight loss for different rotational speed at force $20 \mathrm{~N}$

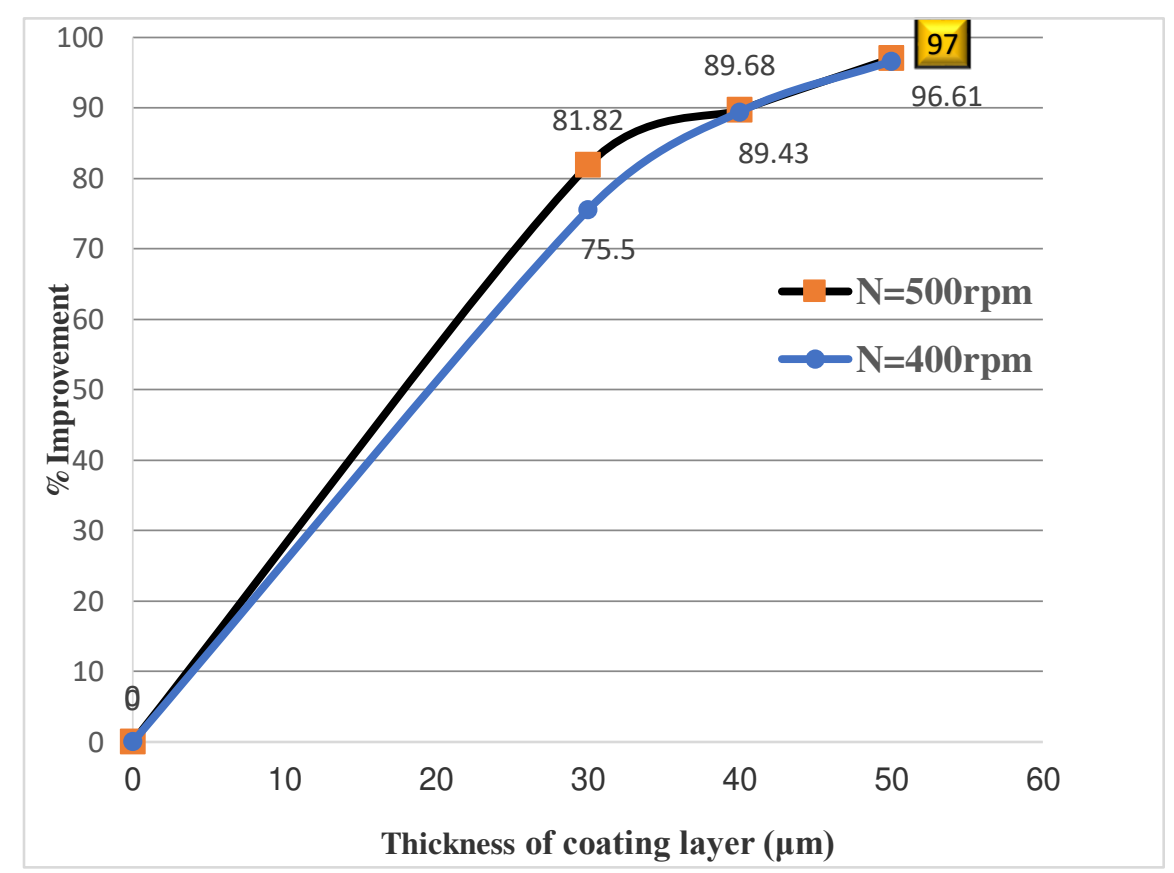

Fig.14. Coating layer thickness with improvement ratio in wear resistance test (Pin on desk).

\subsection{Scanning Electron Microscope (SEM) Image Analysis}

The thickness of the coating layer of the samples was calculated at different coating times by SEM Images and the measurement of the coating thickness was done by the image J soft program. It was found that the layers thicknesses of 30,40 , and $50 \mu \mathrm{m}$ were achieved for coating time of 10, 20, and $30 \mathrm{sec}$, respectively as shown in figure (15). 

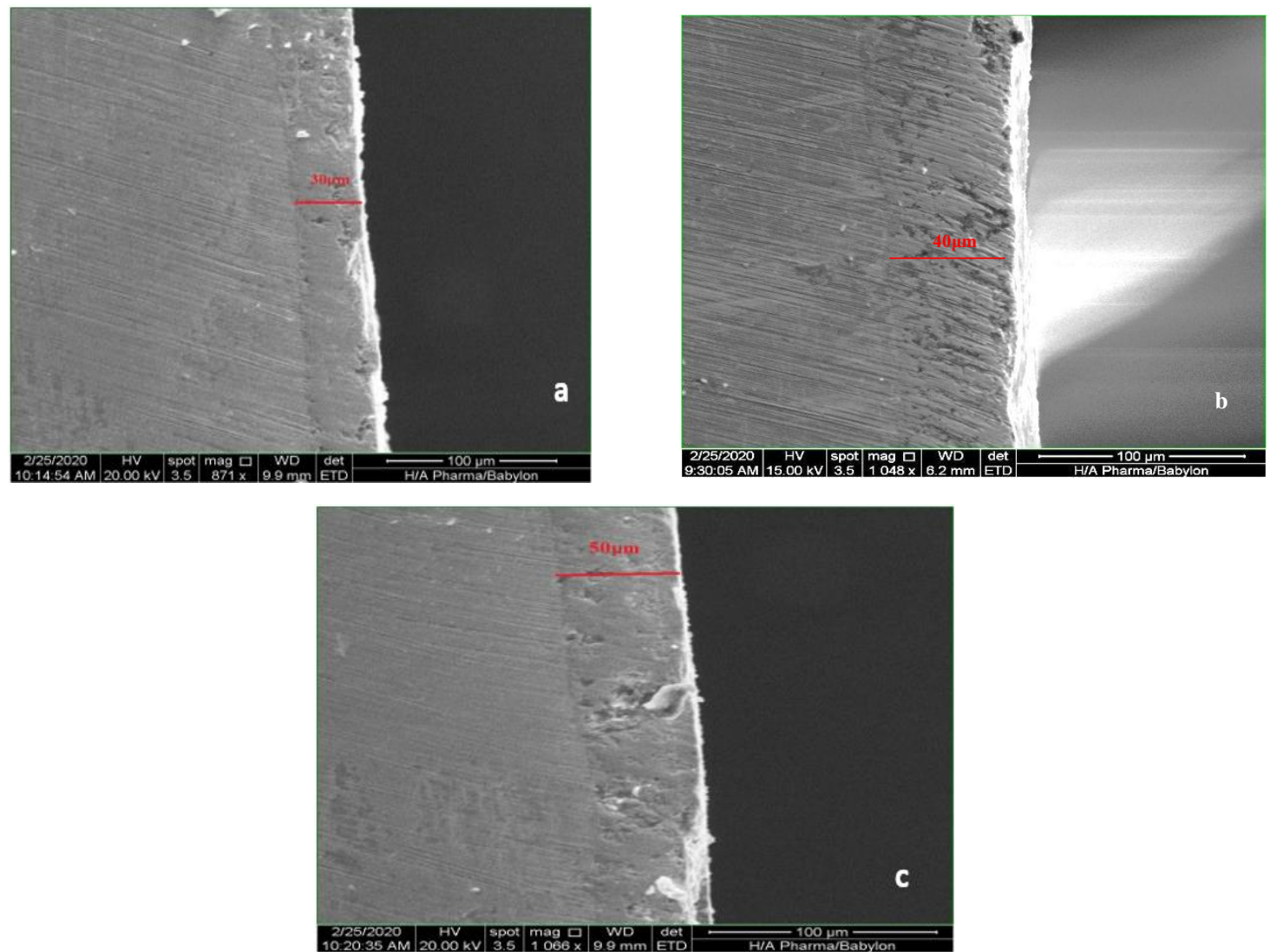

Fig.15. SEM Images for Coating Thickness

(a) $30 \mu \mathrm{m}$, (b) $40 \mu \mathrm{m}$, (c) $50 \mu \mathrm{m} .[21]$

The SEM images showed also the coating time more than $30 \mathrm{sec}$ ( thickness layer more than $50 \mu \mathrm{m}$ ) will produce unstable coating layer that subjected to cracking, flacking, and failure due to lacks of adhesion between the sample surface and coating layer as shown in figure (16)

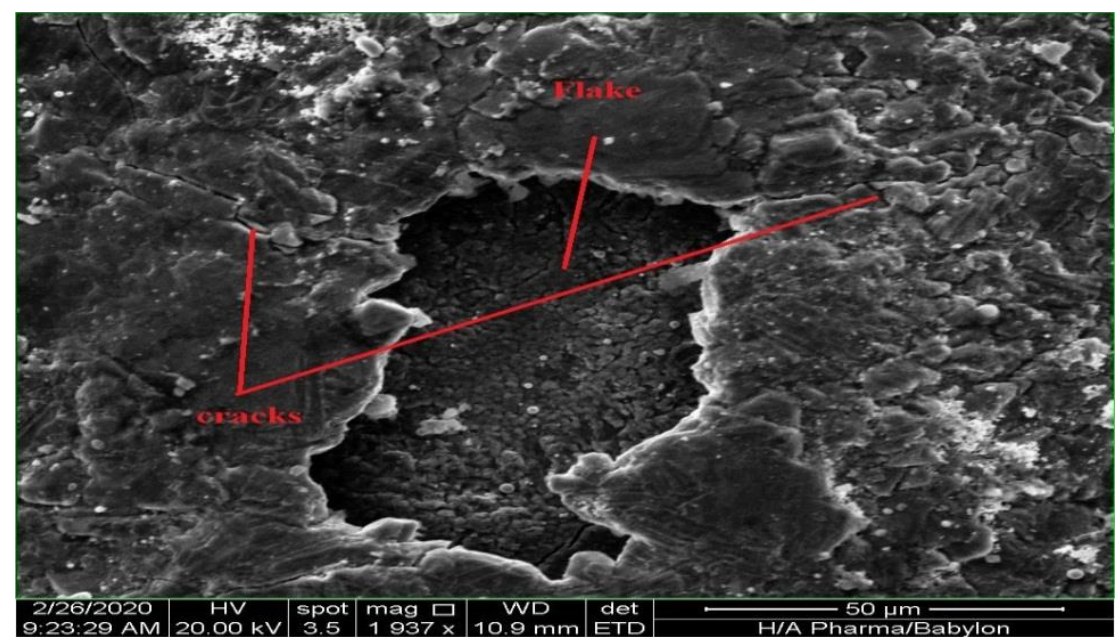

Fig.16. Cracking, Flacking, and failure of coating for coating time more than $30 \mathrm{sec}$ (Coating layer thickness more than $50 \mu \mathrm{m}$ ). 


\subsection{Results of Numerical simulation}

Figure (17) presents the predicted erosion profile distribution for inner surface of elbow with different thicknesses of coating layer as simulation for the real operation test. In this simulation, Oka Correlation used to model the erosion rate. It seen that the erosion rate is reduced by increasing the coating thickness of tungsten carbides nanoparticles, as this coating layer protect the inner surface of elbow from the friction with high velocity cement particles.

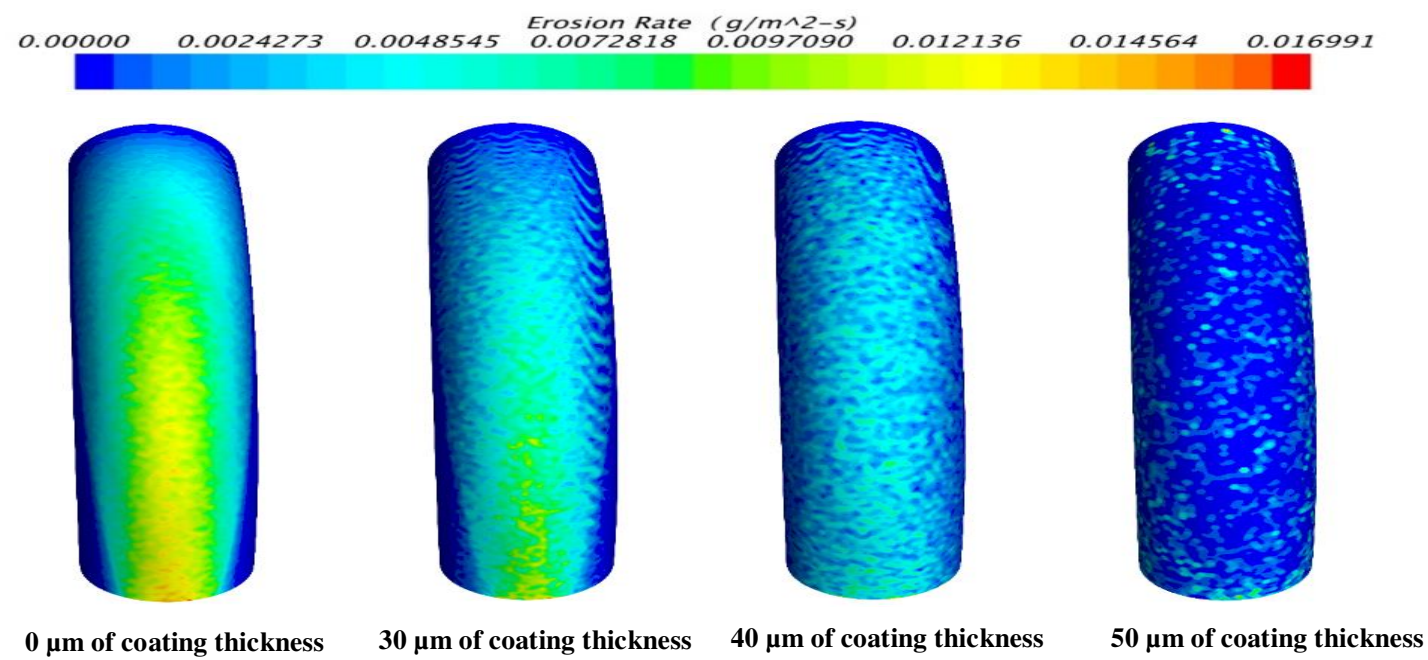

Fig.17. The distributions of the erosion rate profile for the elbow with different values of coating thickness

Figure (18) illustrated validation of the predicted erosion rate with that measured in the experimental work. The erosion rate calculated in $(\mathrm{g} / \mathrm{hr})$ per wall surface area of $(7 * 5 \mathrm{~cm})$. This figure shows a good agreement with the experimental results although a slight disagreement is visible. This mismatch is due to the numerical accuracy and the inlet boundary condition especially the inlet speed which cannot be measured accurately from the cement factory due to measurement difficulties. Figure showed the agreement in erosion rate between the numerical and experimental results for test samples inside elbow under same operational conditions.

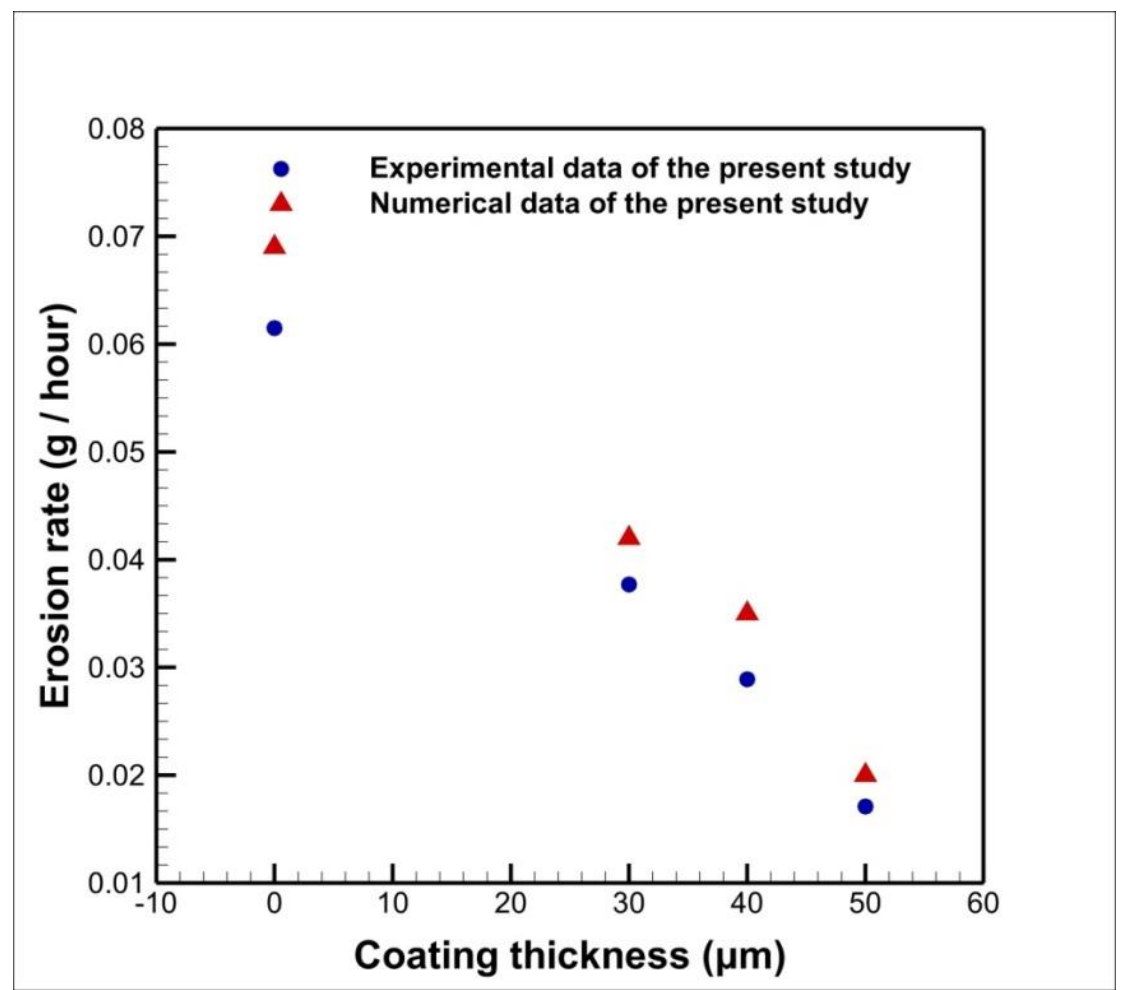

Fig.18. Comparison between the experiment and numerical data for Erosion rates for different coat thickness. 


\section{CONCLUSIONS}

The failure due to mechanical wear in pipes and elbows may cause a lot of loses in money and times for industrial foundations and this failure occur due to Erosion that involves the removal of material from the surface of a component by the high speed impact of a liquid or of a stream of hard particles carried in a fluid flow. The mechanism of erosion occurs when a stream of hard particles is directed at a surface. This may be intended, as in shot blasting processes, or it may arise incidentally, such as in pipe lines and associated components carrying slurries or crude oil containing sand same as pipes and elbows transporting cement powder. This work aimed to find a unique technique to reducing this defect by using Nanoparticle coating with tungsten carbides (WC). This coating technique gave an improvement in wear resistance towards the cement particles flow by $71 \%$ for the sample with $50 \mu \mathrm{m}$ coating thickness that tested inside elbow under same real operation conditions to get a vision about the behavior of coated and uncoated samples inside the elbow in facing the high velocity cement particles flow. The coating layers can recoat after it removal for many times. Also, the improvement in wear resistance for $50 \mu \mathrm{m}$ coating thickness sample that tested by specific standard test of wear (pin on disc) was $97 \%$ higher than samples without coating layer. The result of the pin on disc test indicates the effect of the Nano coat layer which prevents the steel surface from degradation and increasing the operating life of pipes and elbows. The coating layer thickness more than $50 \mu \mathrm{m}$ will subjected to cracking, flacking, and failure due to the lacks in adhesion with steel surface. The numerical simulation that done to compared with test inside elbow show a good agreement between the experimental results and numerical results with convergent reach to $90 \%$.

\section{ACKNOWLEGMENT}

The authors would like to acknowledge the assistance offered by Nanotechnology and Advanced Materials Research Unit (NAMRU), Laboratories of Mechanical Engineering Department at Faculty of Engineering University of Kufa/IRAQ, and mechanical workshop in Kufa cement plant/IRAQ. The author set that there is no fund for this work.

\section{CONFLICT OF INTEREST}

The authors assert that no conflict of interest exists

\section{REFERENCES}

1. Vahid Javaheri, David Porter, Veli-Tapani Kuokkala, " Slurry erosion of steel-Review of tests, mechanisms and materials", Department of Material Engineering and Production Technology, University of Oulu, Wear, 408409, pp.248-273, (2018).

2. Avi Levy and David J. Mason, "Two-layer model for non-suspension gas-solids flow in pipes", Powder Technology 112, 256-262, (2018).

3. Muhammad Mumtaz Mirza, Elansezhian Rasu and Anjali Desilva, Surface Coatings on Steel Pipes Used in Oil and Gas Industries - A Review", American Chemical Science 13(1): 1-23, 2249-0205, (2016).

4. R. Khan, H. H. Ya, W. Pao, and A. Khan, " Erosion-Corrosion of 30॰ $60^{\circ}$, and $90^{\circ}$ Carbon Steel Elbows in a Multiphase Flow Containing Sand Particles ", Materials (MDPI), 12, 23, pp.3898-3912, (2019).

5. K.Shimizu, T. Noguchi, H. Seitoh, E. Muranaka, "FEM analysis of the dependency on impact angle during erosive wear ",Wear, 233-235, 157-159, (2009).

6. Amar Patnaik, Alok Satapathy, Navin Chand, N.M. Barkoula, Sandhyarani Biswas, "Solid particle erosion wear characteristics of fiber and particulate filled polymer composites: A review", Contents lists available at Science Direct, Wear 268, 249-263, (2010).

7. Amit Suhane, Vijay K. Agarwal, " Effect of Bend Geometry on Erosion and Product Degradation in Pneumatic Conveying Pipeline Systems", International Journal of Engineering Research and Applications (IJERA), Vol. 2, Issue 4, pp.129-136, (2012).

8. Vikas Kannojiya, Satish Kumar, Mani Kanwar and S.K. Mohapatra,"Simulation of Erosion Wear in Slurry Pipe Line Using CFD" ,Applied Mechanics and Materials,ISSN:1662-7482,852, pp.459-465, (2016). 
9. P. Baghery, M. Farzam, A.B. Mousavi, M. Hosseini, "Ni-TiO2 Nano composite coating with high resistance to corrosion and wear", Surface \& Coatings Technology, 204, pp.3804-3810, (2010) .

10. Véronique Vitry a, Abdoul-Fatah Kanta b, Fabienne Delaunois," Mechanical and wear characterization of electroless nickel-boron coatings", Surface \& Coatings Technology, 206, pp.1879-1885, (2011).

11. Paul C. Okonkwo, R.A. Shakoor, Essam Ahmed, A.M.A. Mohamed," Erosive wear performance of API X42 pipeline steel", Engineering Failure Analysis 60, 86-95, (2016).

12. Vikas Kannojiya," Computational Modelling of Erosion Wear due to Slurry Flow through a Standard Pipe Bend: Effect of Bend Angle, Orientation, Diameter and Slurry Velocity", Assistant Professor, SGT University, Gurgaon, India, (2018).

13. P. Baghery, M. Farzam, A.B. Mousavi, M. Hosseini,"Ni-TiO2 nanocomposite coating with high resistance to corrosion and wear", Surface \& Coatings Technology 204, 3804-3810, (2010).

14. P. Fauchais and A. Vardelle, "Thermal Sprayed Coatings Used against Corrosion and Corrosive Wear" , chapter in Advanced Plasma Spray Applications Intech. Open, DOI: 10.5772/34448. (2012).

15. Ali Sadiq Alithari, Oday Khadem Mohammed," Wear Resistance Improvement for Grinding Balls of Horizontal Cement Mill in Cement Plant by Nano-Coating Technique", Journal of Mechanical Engineering Research and Developments, Vol. 44, No. 1, pp. 17-27, (2020).

16. ASTM G-99-17," Standard Test Method for Wear Testing with a Pin-on-Disk Apparatus", American Society for Testing and Materials, (2017)

17. H. K. Versteeg and W. Malalasekera, an Introduction to Computational Fluid Dynamics, Second Edi. England: Pearson education, (2017).

18. Clift R, Grace JR, Weber ME., Bubbles, drops, and particles. USA: Academic Press;(2016).

19. Oka, Y.I, Okamura, K., and Yoshida, T.. "Practical estimation of erosion damage caused by solid particle impact. Part 1: Effect of impact parameters on a predictive equation”, Wear , 259, pp. 95-110, (2005).

20. Oka, Y.I., and Yoshida, T. "Practical estimation of erosion damage caused by solid particle impact. Part 2: Mechanical properties of materials directly associated with erosion damage”, Wear, 259, pp. 102-109, (2005).

21. Ali Sadiq Alithari, Layth Zbbal Abd UL Kareem and Nabeel AL-Zurfi," Influence of Adding Nano Coating Layers on the Hardness and Impact strength Properties for Low Carbon Steel", IOP Conf. Series: Materials Science and Engineering, 1094 (2021) 012137, doi:10.1088/1757-899X/1094/1/012137 
Figures

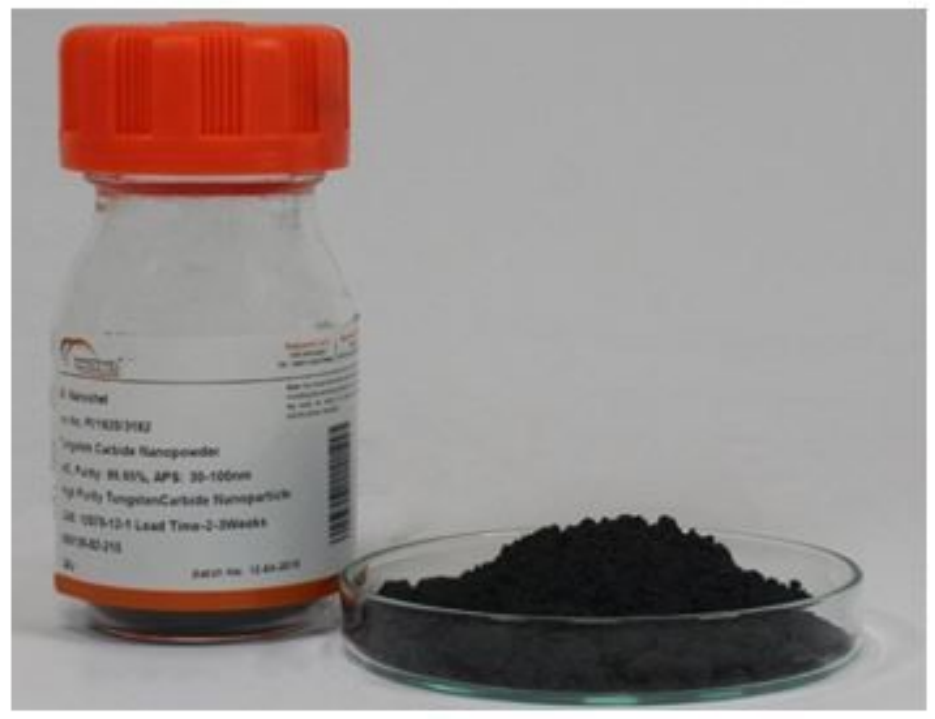

Figure 1

Nanoparticles of Tungsten Carbide (WC) .[13]

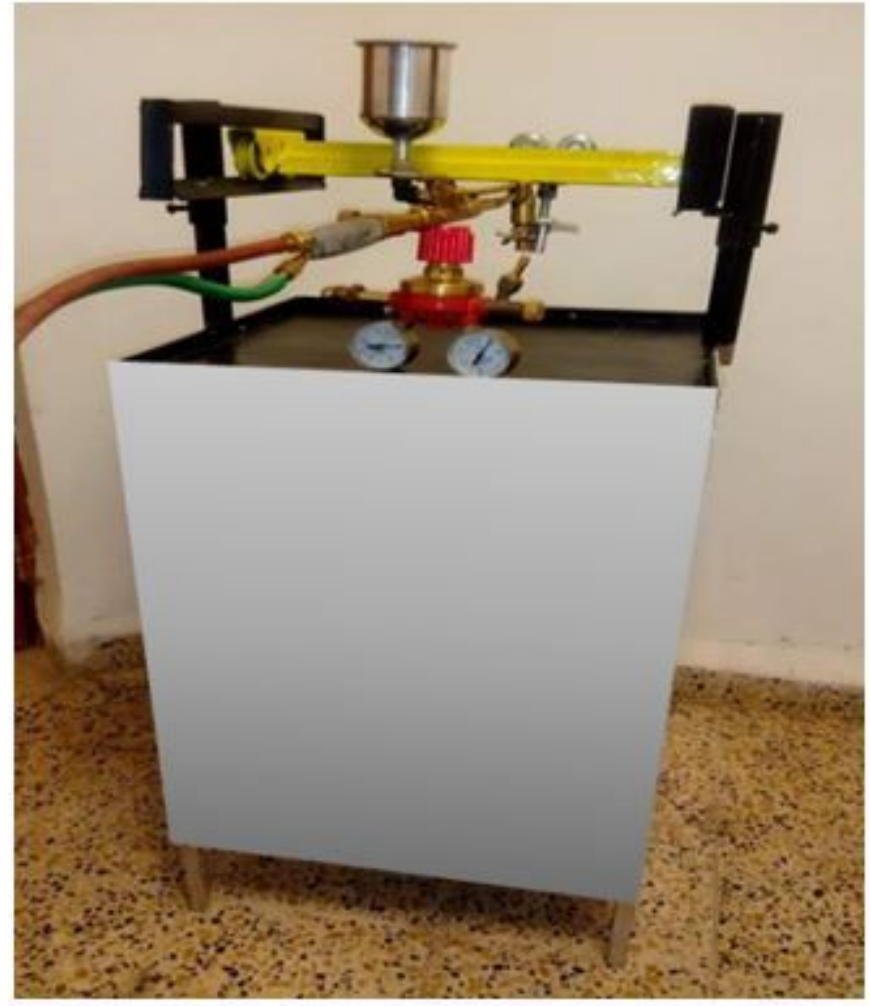

Figure 2

HVOF System.[15] 


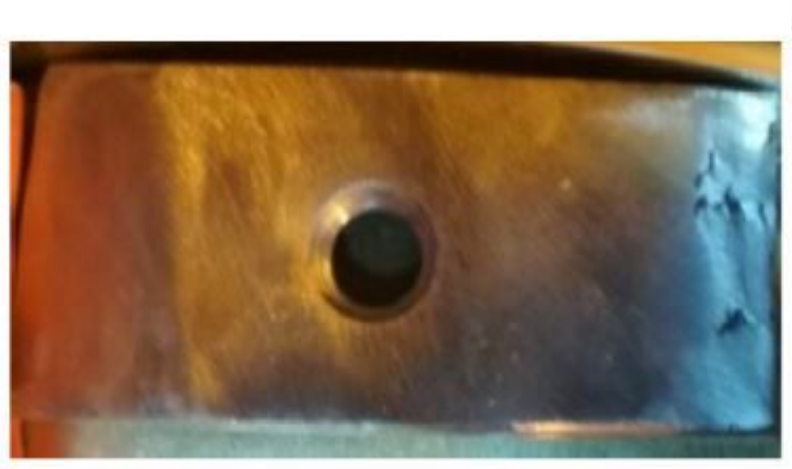

$5 \mathrm{~mm}$

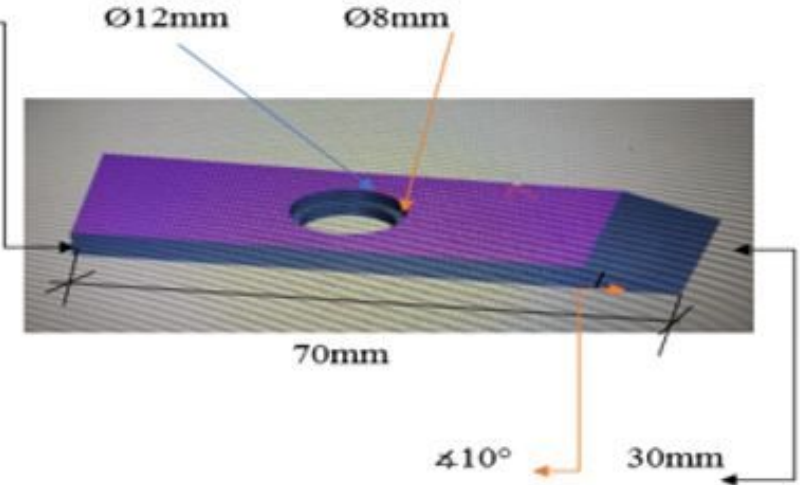

Figure 3

Samples inside Elbow
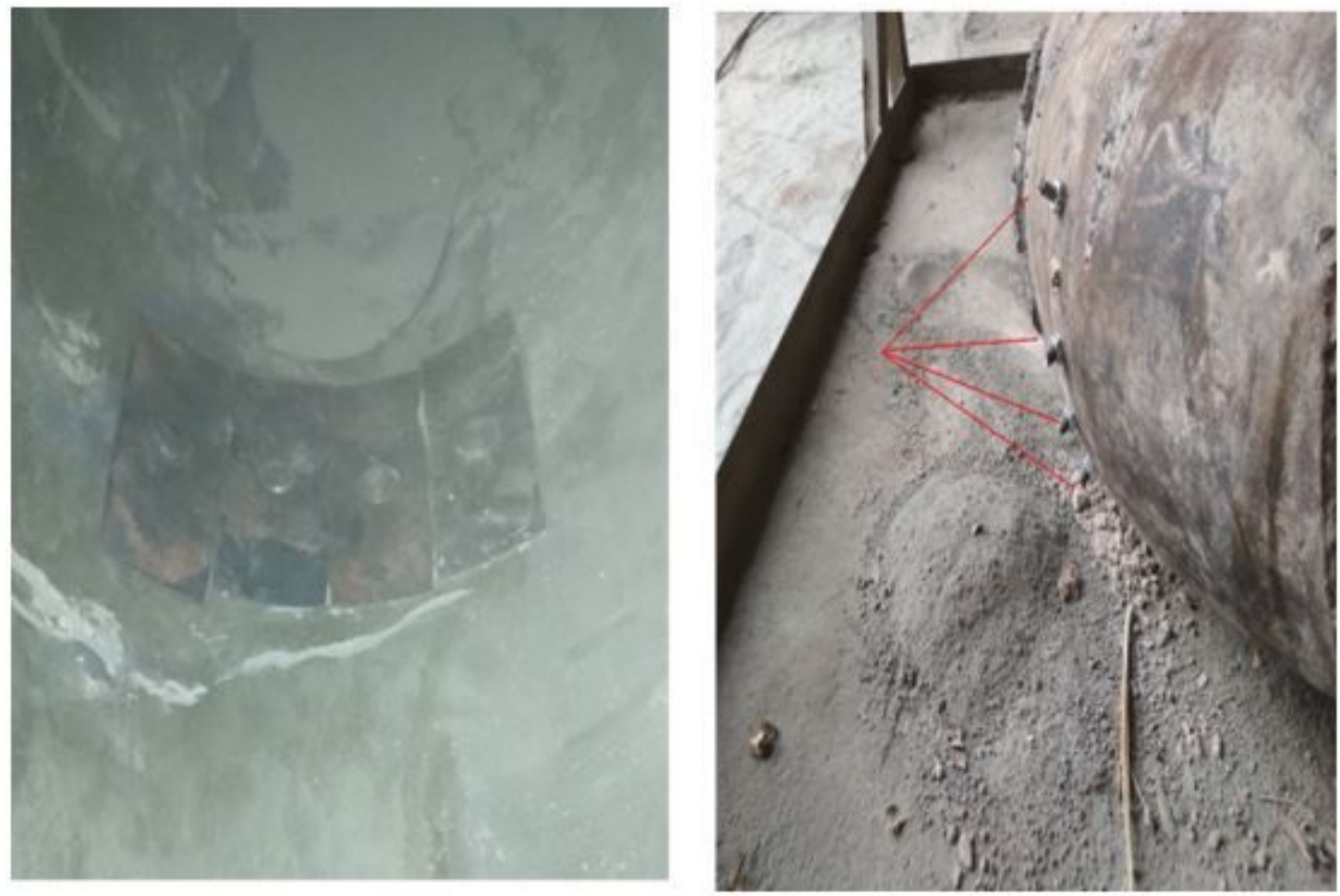

Figure 4

Samples Installation inside the Elbow 


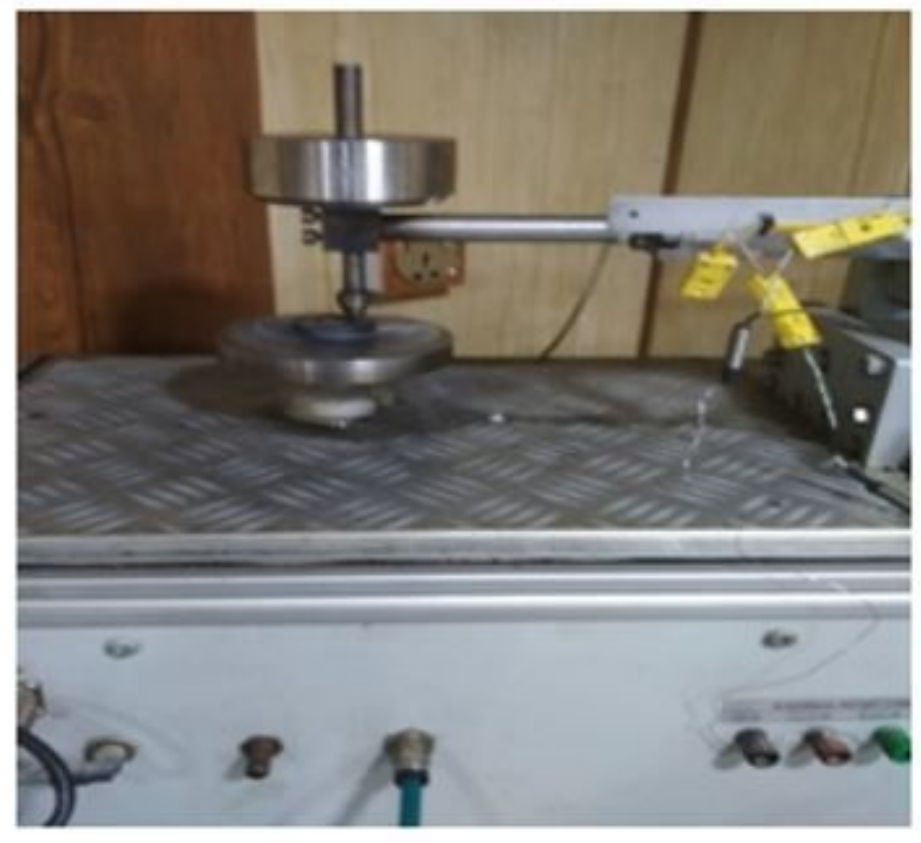

Figure 5

Pin on Disc Tester

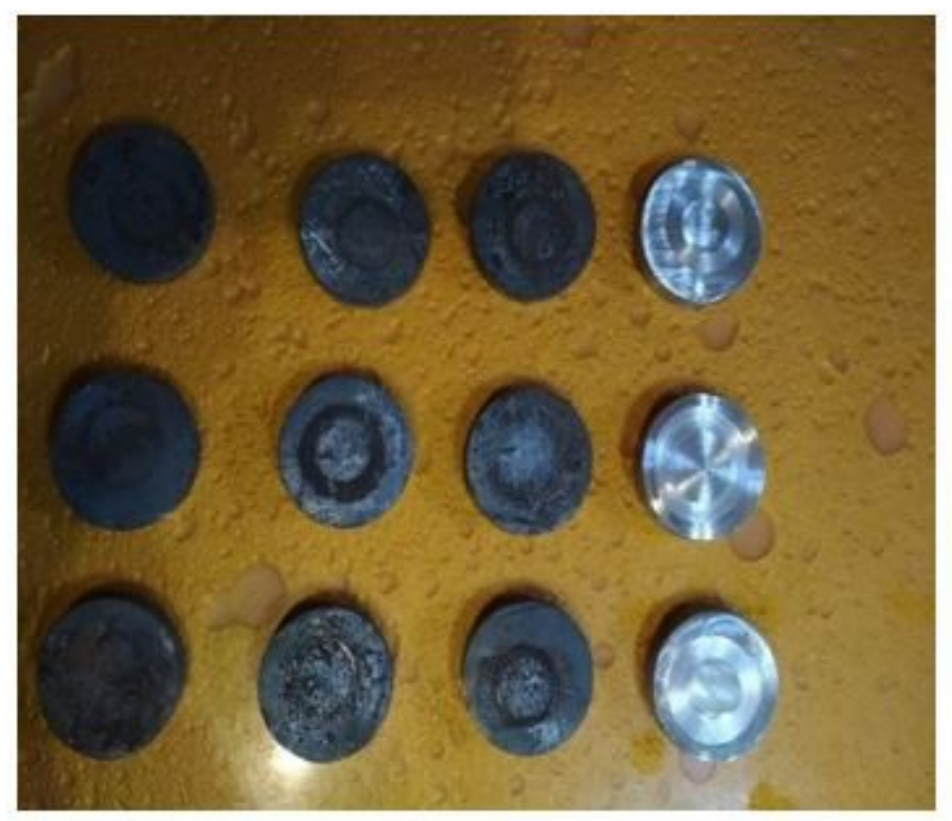

Figure 6

Wear samples Test after Testing (Coated and uncoated) 


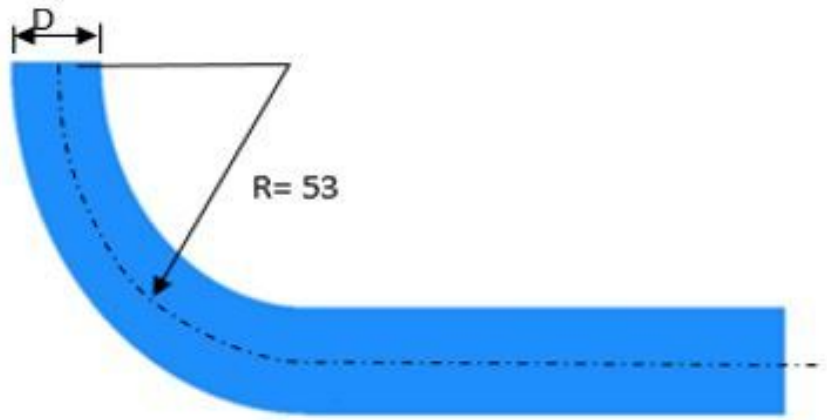

(a) Schematic of standard elbow geometry

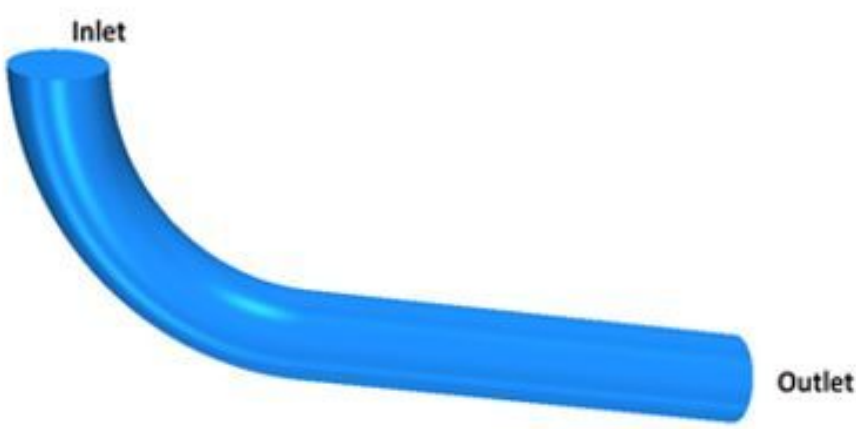

(b) 3- D elbow geometry.

\section{Figure 7}

Schematic of the elbow.

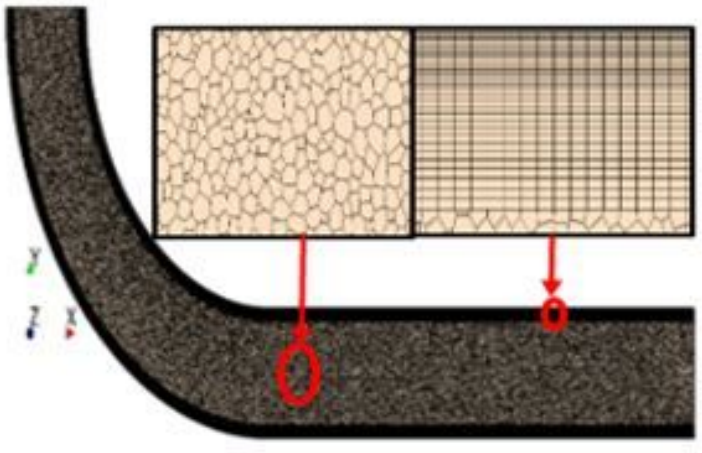

(a) Elbow section mesh

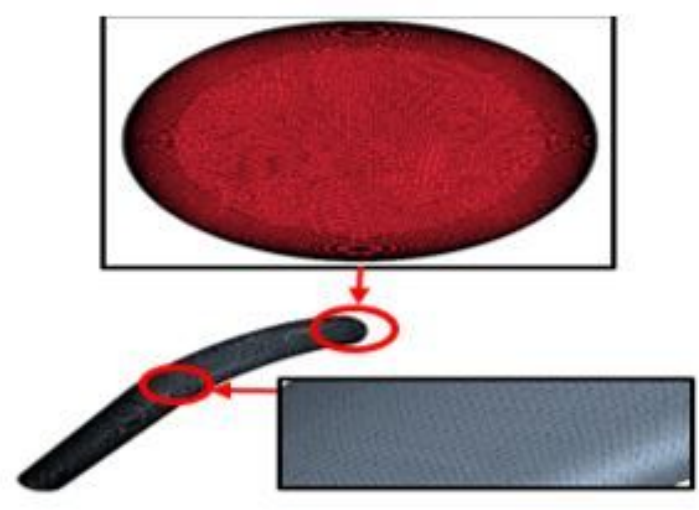

(b) Surface mesh on and around the extrados and inlet of the elbow

\section{Figure 8}

Mesh of elbows model. 


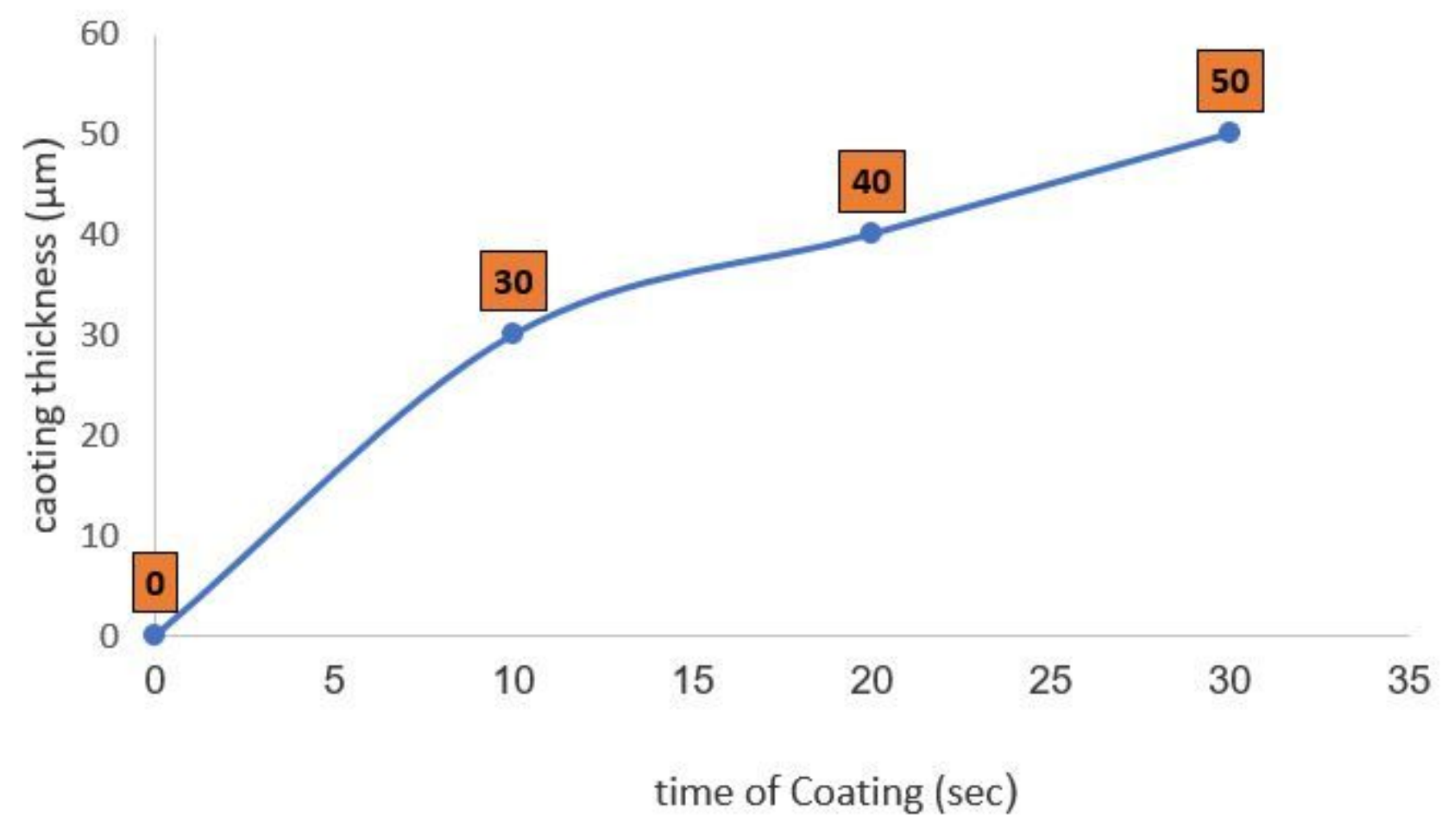

Figure 9

Coating layer thickness in $(\mu \mathrm{m})$ with time of coating(sec). 


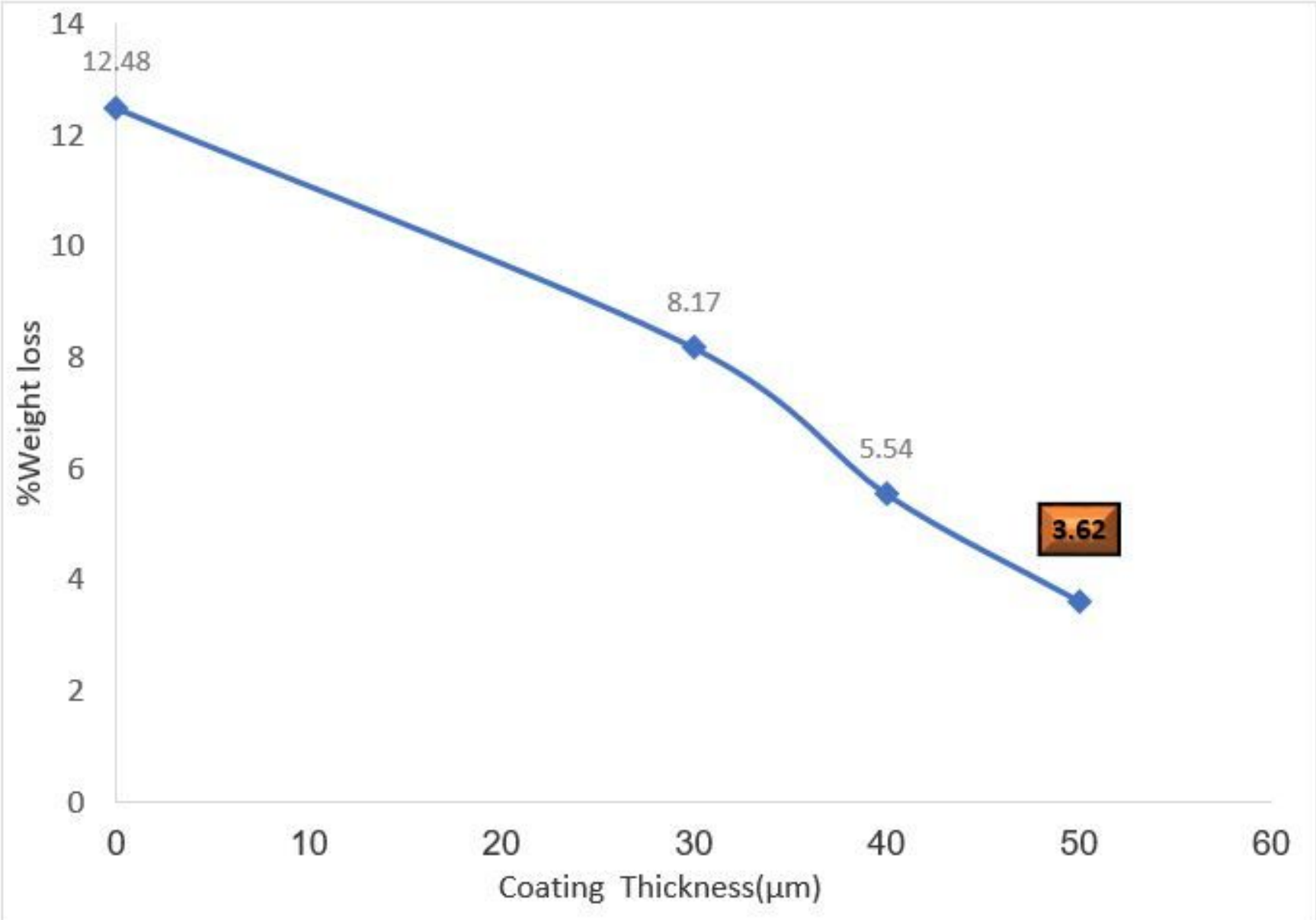

Figure 10

The weight Loss ratio with Coat Thickness of Samples inside Elbow 


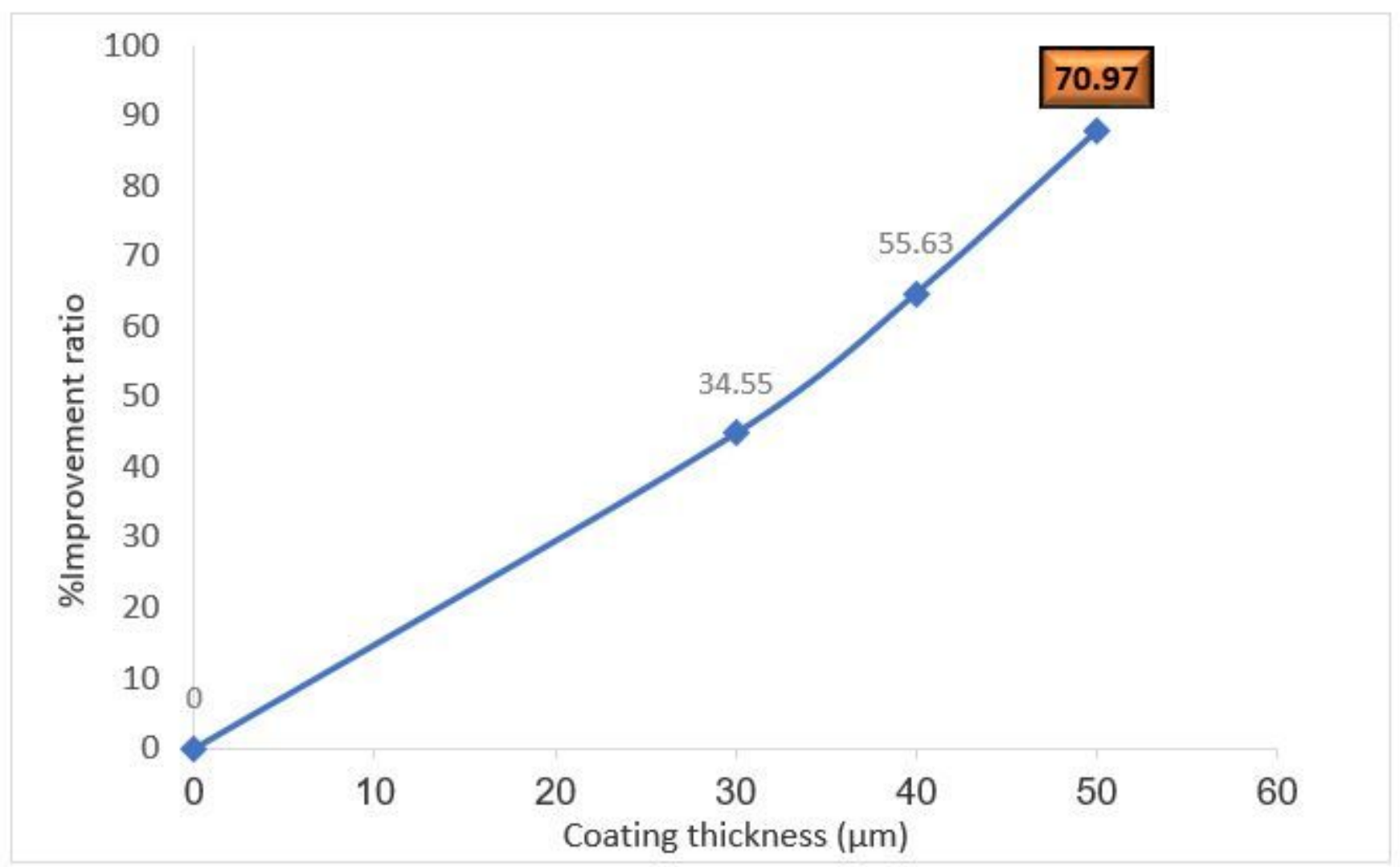

Figure 11

Improvement ratio of Wear resistance for samples inside the elbow

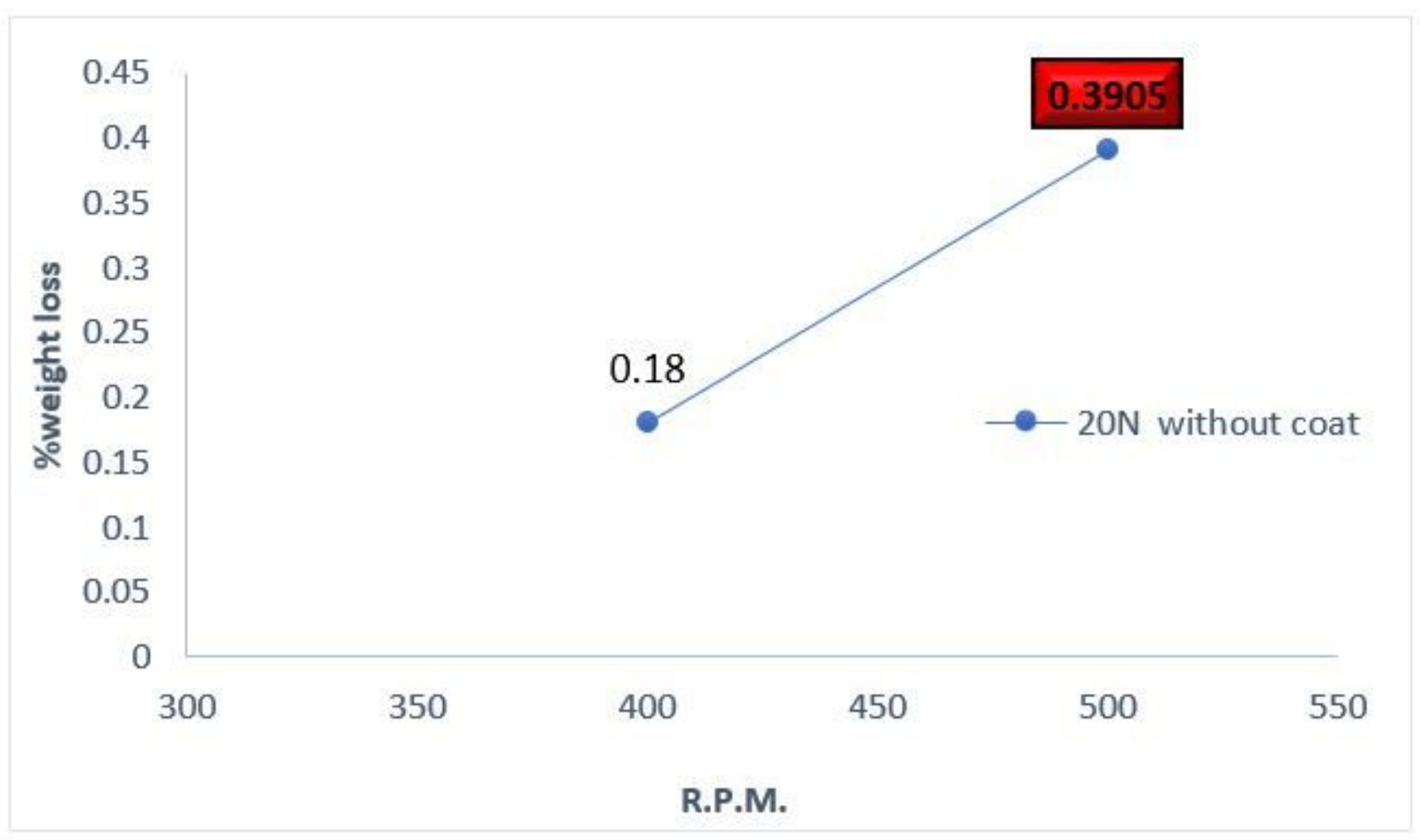


Figure 12

Weight loss with angular velocity for uncoated samples .

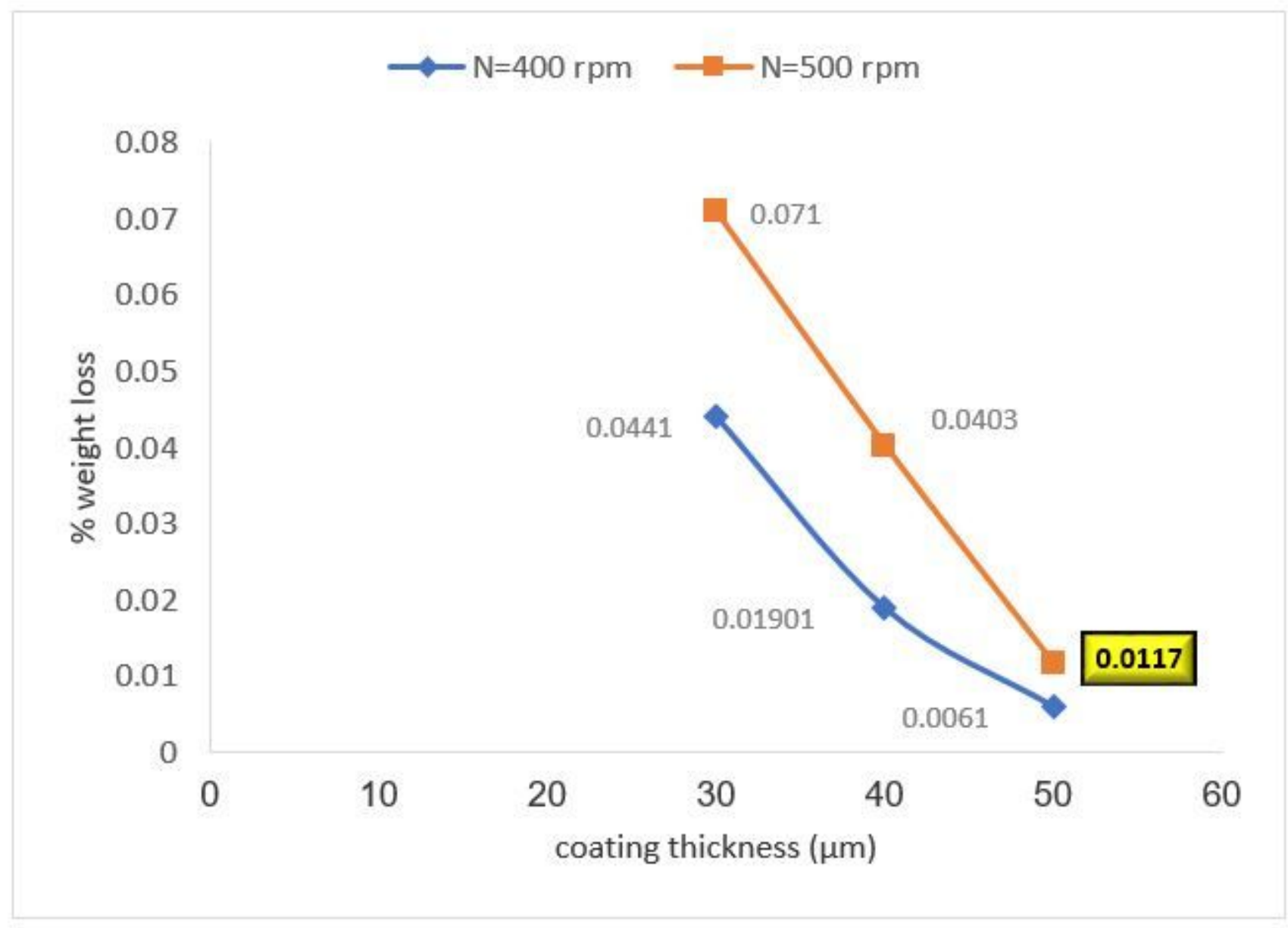

Figure 13

Coating layer thickness and weight loss for different rotational speed at force $20 \mathrm{~N}$ 


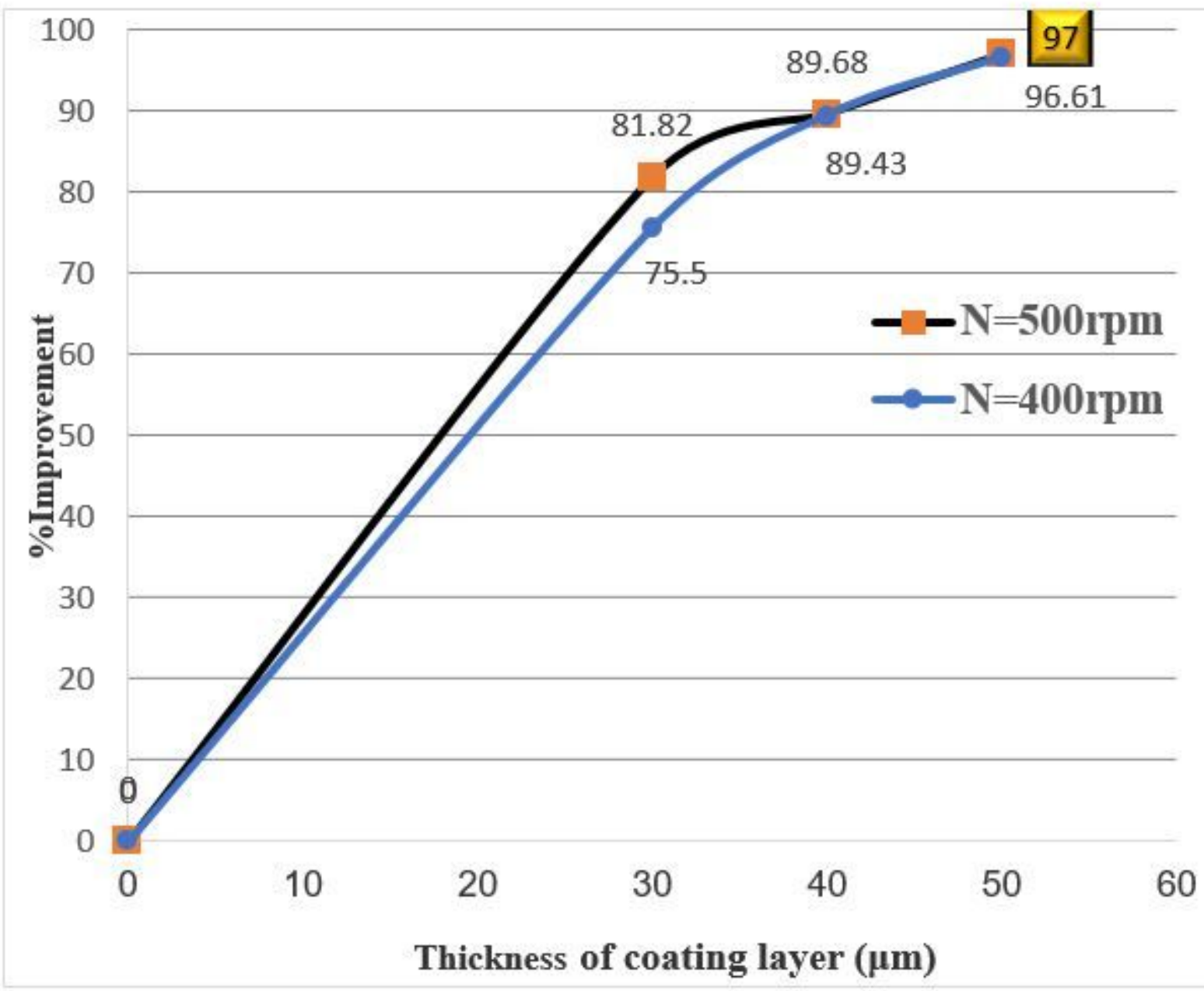

Figure 14

Coating layer thickness with improvement ratio in wear resistance test (Pin on desk). 

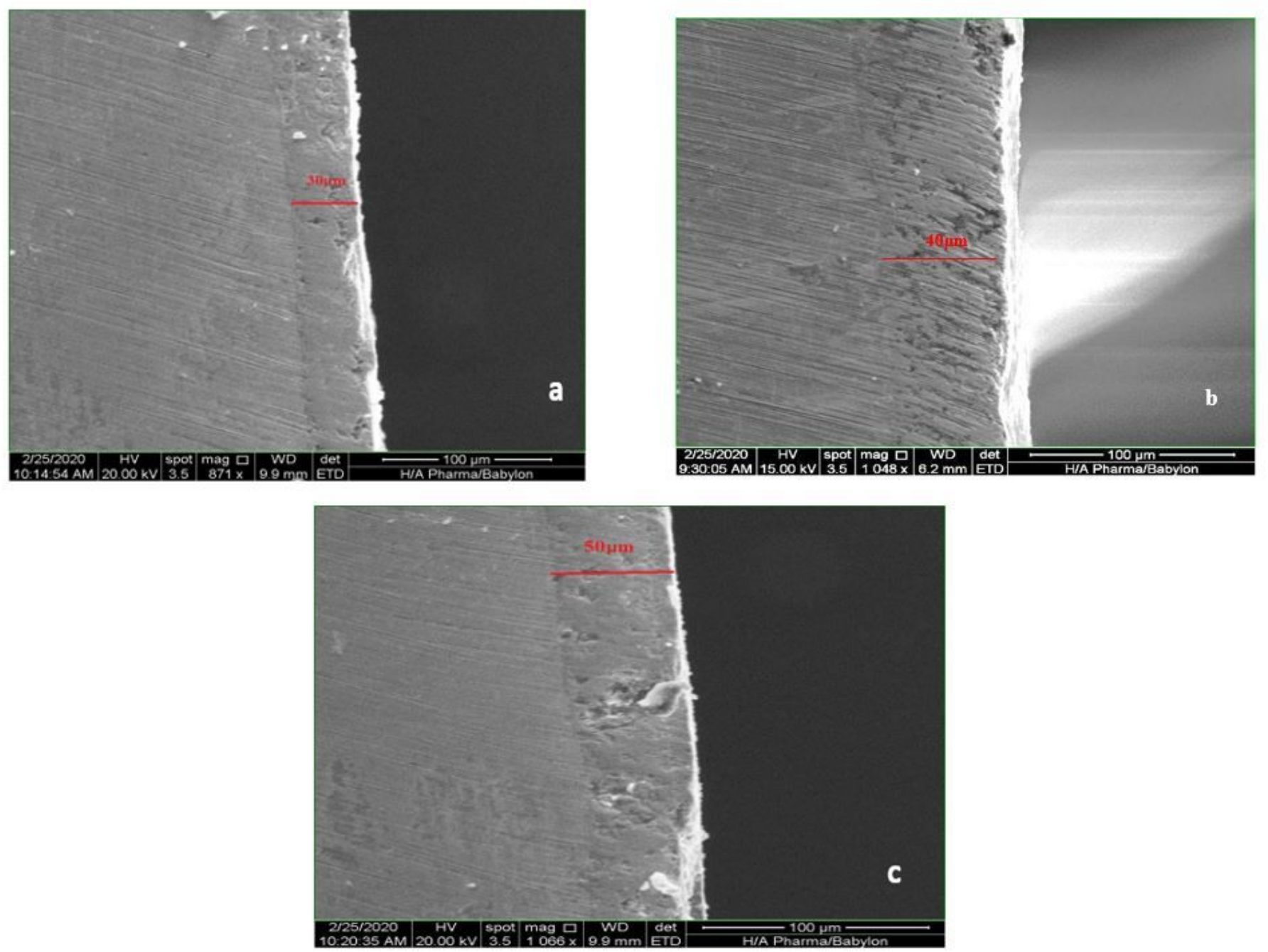

Figure 15

SEM Images for Coating Thickness (a) $30 \mu \mathrm{m}$, (b) $40 \mu \mathrm{m}$, (c) $50 \mu \mathrm{m}$.[21] 


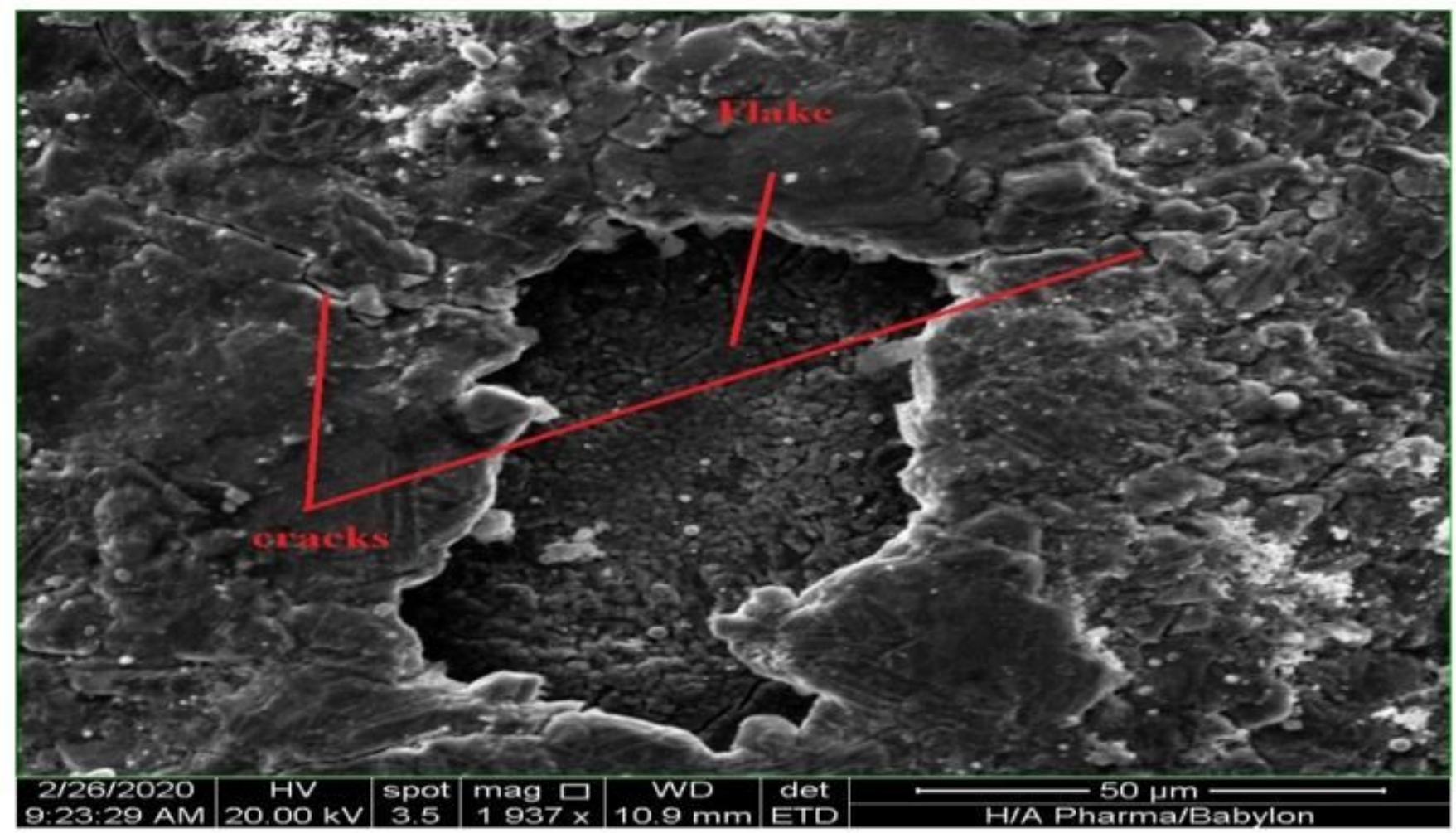

\section{Figure 16}

Cracking, Flacking, and failure of coating for coating time more than $30 \mathrm{sec}$ (Coating layer thickness more than $50 \mu \mathrm{m})$.

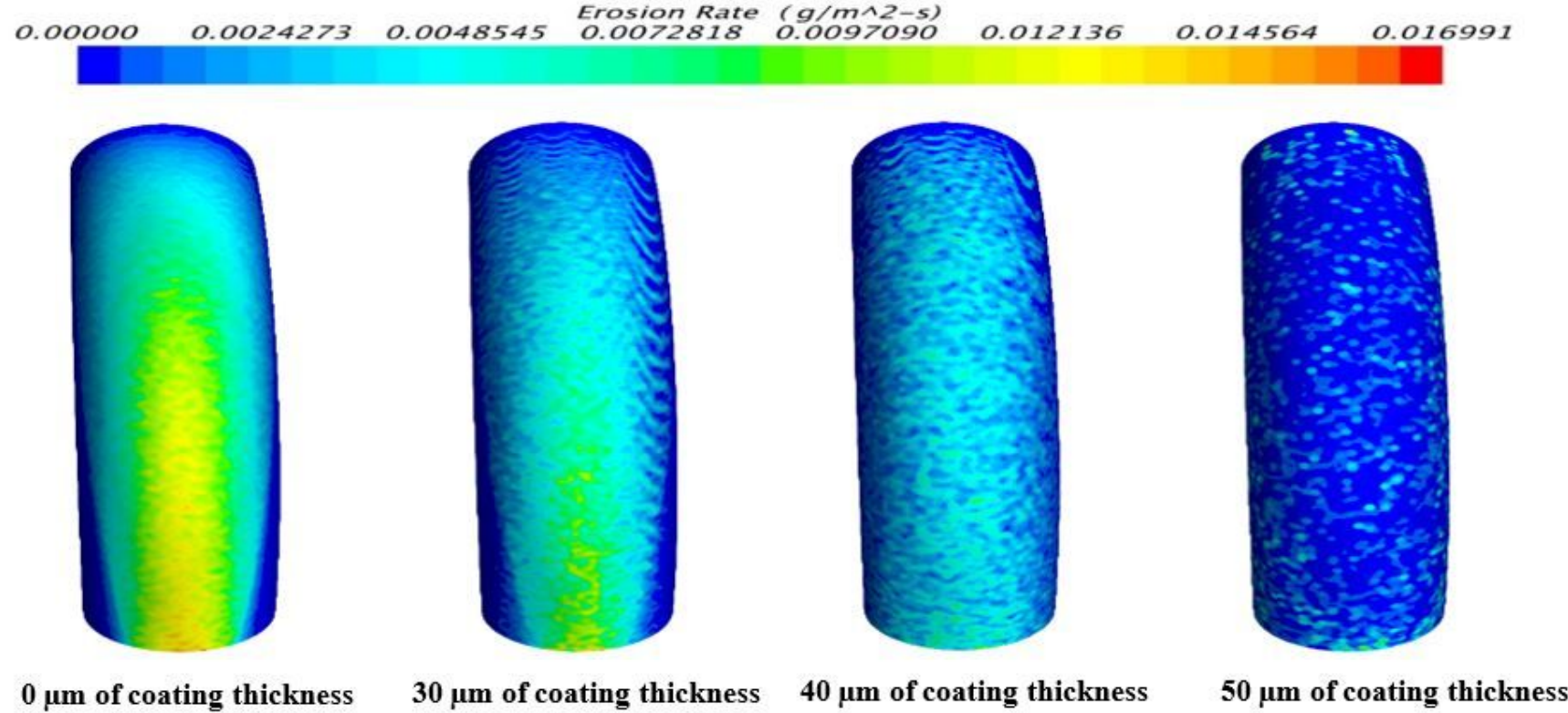

Figure 17

The distributions of the erosion rate profile for the elbow with different values of coating thickness 


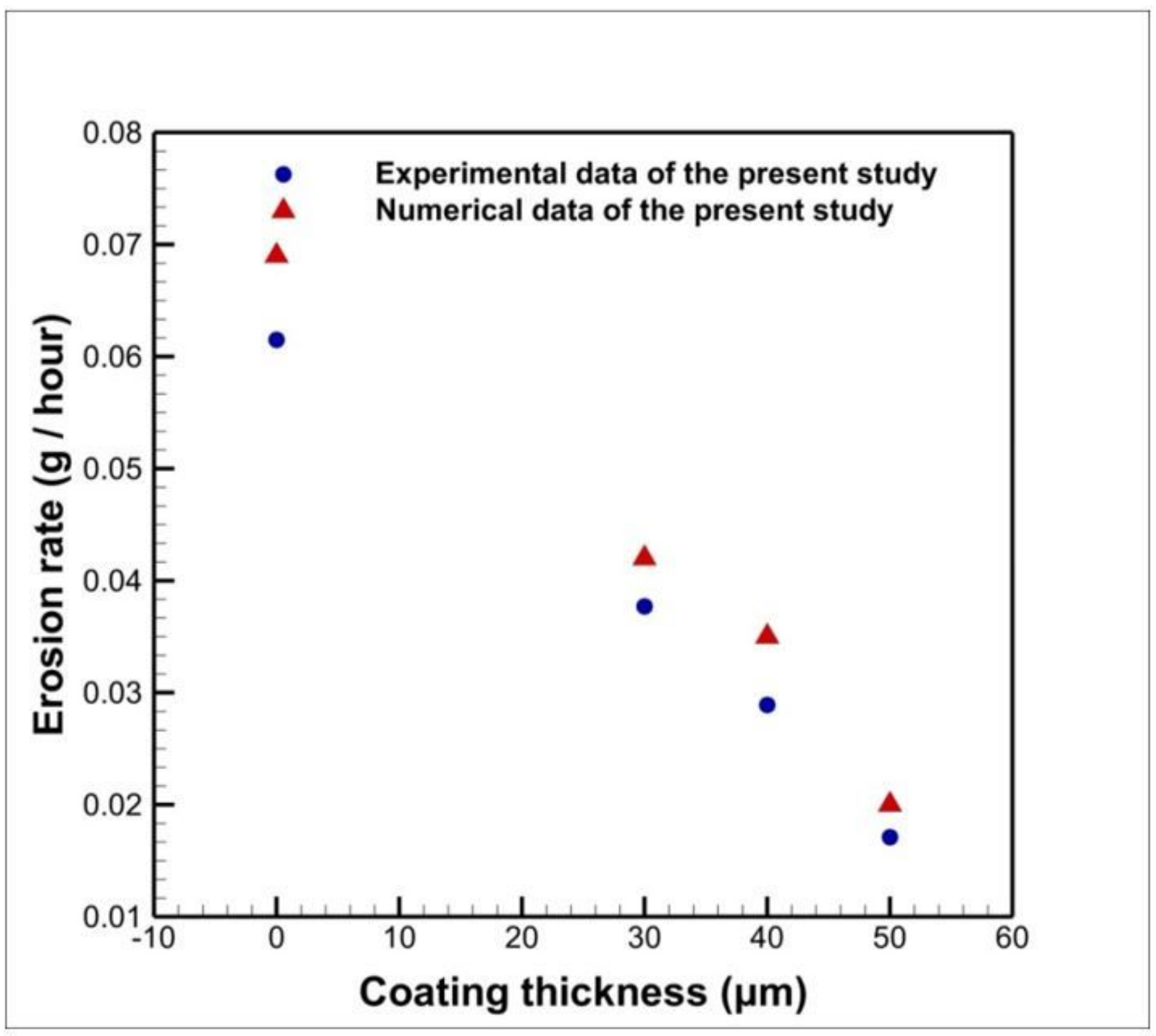

Figure 18

Comparison between the experiment and numerical data for Erosion rates for different coat thickness. 